\title{
The Supplemental Nutrition Assistance Program, Energy Balance, and Weight Gain
}

December 20, 2015

\begin{abstract}
Between 2001 and 2006, women participating in the U.S. Supplemental Nutrition Assistance Program (SNAP) weighed 15.5 pounds more than eligible nonparticipants on average. Using a dataset (NHANES) that contains detailed information on a wide variety of demographic, socioeconomic, health and behavioral characteristics for 2,018 SNAP-eligible women, we make three contributions to the growing literature that addresses this weight difference. First, we specify a physiological model of weight gain with which we show that average differences in caloric intake and physical activity are much too small to explain the weight difference. Second, we estimate regression models that show SNAP participation is not associated with changes in energy balance (i.e., caloric intake and physical activity). Third, we estimate regression models that show SNAP participation does not predict significant weight gain. Our results provide no support for the hypothesis that SNAP participation causes weight gain.
\end{abstract}

Key Words: Food Stamp Program (FSP), Supplemental Nutrition Assistance Program (SNAP), obesity, weight gain, energy balance, food assistance, nutrition assistance.

This project was supported by a cooperative grant from the USDA Economic Research Service, Food and Nutrition Research Program, Agreement \#58-5000-0-0045. We also gratefully acknowledge financial and indirect support from the University of California Agricultural Issues Center and the Giannini Foundation of Agricultural Economics. We appreciate the many helpful suggestions from Abigail Okrent, Daniel Sumner, Jim Wilen, Hilary Hoynes, and Parke Wilde, as well as others who participated in a brownbag seminar.

The findings and conclusions in this paper are those of the authors and do not necessarily represent the views of the Research Data Center, the National Center for Health Statistics, the Centers for Disease Control and Prevention, or the U.S. Department of Agriculture Economic Research Service. Data collection for NHANES was approved by the NCHS Research Ethics Review Board. Analysis of deidentified data from the survey is exempt from the federal regulations for the protection of human research participants. Analysis of restricted data through the NCHS Research Data Center is also approved by the NCHS ERB.

(C) 2016. This manuscript version is made available under the Elsevier user license http://www.elsevier.com/open-access/userlicense/1.0/ 


\section{Introduction}

Between 1960 and 2009 the percentage of adults in the United States classified as overweight or obese (having a body mass index (BMI) greater than 25) increased from $41 \%$ to $68 \%$ (Flegal 1998; Levi et al. 2010) $\mathrm{I}^{1}$ This paper concerns the link between the rise in obesity and participation in the Supplemental Nutrition Assistance Program (SNAP). Prior studies have demonstrated that female SNAP participants are more likely to be overweight or obese than eligible nonparticipants (e.g., Gibson 2003). Does the additional income provided through SNAP benefits induce participants to eat significantly more than they would otherwise, and thus making participants heavier?

SNAP has functioned as the mainstay of U.S. food assistance programs for over 40 years.2 In 2014, 46.5 million Americans (15\% of the population) participated, receiving an average of $\$ 125$ per person per month of enrollment. In that year, $72 \%$ of the $\$ 103.4$ billion spent on food assistance was delivered through SNAP benefits..$^{3}$ Previous studies have applied a wide variety of methods to estimate the effect of SNAP on obesity and have yielded mixed results (e.g., Devaney and Moffitt 1991; Townsend et al. 2001; Gibson 2003; Chen, Yen, and Eastwood 2005; Baum 2007; Ver Ploeg et al. 2007; Meyerhoefer and Pylypchuk 2008; Ver Ploeg and Ralston 2008; Fan 2010).

We present a range of evidence, all of which is consistent with the view that SNAP participation has not caused higher obesity rates. First, using a physiological model of

\footnotetext{
${ }^{1} \mathrm{BMI}$ is calculated as the ratio of weight $(\mathrm{kg})$ to height squared $\left(\mathrm{m}^{2}\right)$.

${ }^{2}$ The Food Stamp Program was renamed the Supplemental Nutrition Assistance Program in October, 2008.

${ }^{3}$ SNAP and total U.S. Department of Agriculture (USDA) expenditures are taken from Food and Nutrition Services program data, available at: http://www.fns.usda.gov/pd/SNAPsummary.htm and http://www. fns.usda.gov/pd/annual.htm.
} 
weight gain, we find that differences in average energy consumption and physical activity are much too small to explain the observed weight difference between SNAP participants and non-participants. Second, using reduced-form regression models of energy balance and controlling for a set of observables, we find that SNAP participation is not even positively related to caloric intake and has only a small negative relationship with physical activity. Third, we estimate a reduced-form model of weight gain and find no significant additional weight gain by SNAP participants. Although we cannot formally test for causality, the absence of a significant correlation between participation and weight gain suggests that a causal relationship does not exist.

The observed correlation between weight and SNAP participation could be explained, alternatively, if obesity influences the SNAP participation decision or if weight and participation are jointly determined by other causes. In other words, understanding the correlation between SNAP participation and weight requires understanding the determinants of SNAP participation. To that end, we develop a model of program participation in which body weight can influence the choice to participate in SNAP. Although previous research suggests “...women with higher proclivities for obesity are more likely to participate..." (Ver Ploeg and Ralston 2008), to our knowledge, no-one else has specifically investigated whether individual propensities for obesity influence the decision to participate in SNAP. Our estimates show a strong and statistically significant relationship between obesity and the propensity to participate in SNAP. 


\section{Previous Work on Obesity and SNAP Participation}

The gross correlation between body weight (or BMI) and participation in SNAP is apparent in the data. Figure 1 plots body weight as a nonparametric function of age for SNAP participant:4 $\mathrm{4}^{4}$ and separately for nonparticipants, based on pooled data from the 2001-2002, 2003-2004, and 2005-2006 National Health and Nutrition Examination Surveys (NHANES) [5 $^{5}$ SNAP participants were almost 20 pounds heavier than eligible nonparticipants among 1840 year-old women during this period. The difference is smaller for older women than for young women; it averages less than 10 pounds for women over 50.

[Figure 1. Weight and Age for Women by SNAP Program Status]

Figure 1 suggests a link between SNAP participation and obesity, but the obesity issue is very complex, with multiple potential contributing factors such that simple correlation does not establish causation (see Smith, 2009, for a review of the literature and evidence on the links between poverty, income assistance, and obesity in the United States).

SNAP participation could promote obesity by increasing the amount of food consumed above what would have been consumed otherwise, decreasing the amount of time available for physical activity, or both. However, a recent systematic review of the evidence on the differences in energy consumption, dietary patterns (e.g., sugar sweetened beverage consumption), and diet quality between SNAP participants and income eligible non-participants found mixed results and no conclusive evidence that participation changes dietary patterns for the worse (Andreyeva, Tripp, and Schwartz 2015).

\footnotetext{
${ }^{4}$ We define a participant as a female respondent who reported living in a household that received SNAP benefits in at least one of the past 12 months.

${ }^{5}$ See Section 3 for more information about the data.
} 
Using both longitudinal and cross-sectional data, several investigations have documented the connection between SNAP participation or poverty and obesity, reporting mixed results as to the direction of causation and the magnitude of the effect (see Drewnowski and Specter 2004, and Smith 2009 for reviews of the literature). The relationship between SNAP participation and obesity has been observed only in women. Townsend et al. (2001) found that low-income women on SNAP had a 38\% greater probability of being overweight (defined as having a BMI $>27.3$ in the study). Similarly, Gibson (2003) found a significantly increased risk of being obese (defined as having a BMI $\geq 30$ ) for low-income women currently participating in SNAP, and more so for long-term female SNAP participants. In agreement with Gibson (2003), Chen, Yen, and Eastwood (2005) and Baum (2007) also found that SNAP participation had a positive and significant relationship with BMI and obesity for women, but not for men. Similarly, Meyerhoefer and Pylypchuk (2008) found that female SNAP participants had a $2.5 \%$ lower chance of being categorized as normal or underweight (BMI < 25), a much smaller estimated effect than found by Townsend et al. (2001), Gibson (2003), and Chen, Yen and Eastwood (2005).

Employing the data from the NHANES II (1976-80), III (1988-94), and 1999-2002 continuing survey, Ver Ploeg et al. (2007) demonstrated that, in more recent rounds of the NHANES survey, there was no longer a "BMI gap" between white female participants and nonparticipants. However, this analysis controlled only for a quadratic function of age, included women ineligible for SNAP, and did not use the dietary intake information collected by NHANES. Using data from the National Health Interview Survey to exploit the natural experiment that resulted from foreign-born immigrants in some states losing SNAP eligibility after the enactment of the Personal Responsibility and Work Opportunity Reconciliation Act 
in 1996, Kaushal (2007) found no evidence that SNAP participation significantly increased the BMIs of low-income immigrant mothers.

Zagorsky and Smith (2009) used the NLSY79 to evaluate the BMIs of individuals who had participated in SNAP during a given year, and found that the BMIs of female SNAP participants were 1.24 units greater than the BMIs of nonparticipants. Also using the NLSY79, but applying propensity-score matching techniques to control for pre-participation weight and other socio-economic and demographic factors, Fan (2010) found that participation in SNAP had no significant effect on BMI or obesity among low-income women. Both Zagorsky and Smith (2009) and Fan (2010) controlled for individual characteristics such as race, education, gender, marital status, homeownership, state of residence, and household income. Fan (2010) and Baum (2007), who also used the NLSY79, in effect modeled weight gain by controlling for pre-participation body weight.

Three pieces of evidence from outside this literature cast doubt on the hypothesis that SNAP participation causes obesity. First, the direction of causation could run from obesity to poverty, and thus, from obesity to welfare participation. For instance, Cawley (2004) found that having a high body weight is associated with significantly lower wage rates for white women. Even holding income constant, characteristics that make individuals more susceptible to weight gain may be associated with other characteristics that cause people to be less economically secure and more likely to participate in SNAP. This possibility underlies the importance of accounting for selection bias in cross-sectional regressions of weight or BMI on SNAP participation. Notably, Fan (2010), who used propensity score matching, and Kaushal (2007), who exploited a natural experiment, found no causal effect of SNAP participation on obesity once they accounted for selection bias. 
Second, the hypothesis that increasing the purchasing power of a low-income household would result in negative health outcomes contradicts the much-studied and well-documented "health-wealth gradient," that is, the positive association between measures of socio-economic status and good health. ${ }^{6}$ For instance, one popular hypothesis is that the extra income for food afforded by participation in SNAP induces increases in caloric intake, which explains the higher prevalence of obesity among women who participate in SNAP. In this scenario, we might expect the poorest households, for whom SNAP benefits comprise a larger fraction of total income, to have the greatest increase in food consumption (Wilde, Troy, and Rogers 2009). However, as Figure 2 demonstrates, the difference in weight between participants and nonparticipants is not greater for poorer women than women near the gross income cutoff for SNAP eligibility (income-to-poverty ratio $=1.85$ ).

[Figure 2. Weight by Income-to-Poverty Ratio for Women by SNAP Status]

Third, in the 1990s and early 2000s over half of participating households exited SNAP within eight to ten months of beginning a new SNAP participation spell (Cody et al. 2005; Cody et al. 2007). Between 2004 and 2006, 60\% of participating households had multiple participation spells, with a median total spell length of 18 months and a median time-off between spells of 20 months. During the same time period, $65 \%$ of participating households had a total participation spell length of 24 months or less, suggesting that if SNAP participation increases food consumption and causes weight gain, it has a window of at most two years in which to do so for most households (Mabli et al. 2011). Moreover, as Figure 1 shows, a large weight gap exists even for women as young as 18, who must have participated in SNAP

\footnotetext{
${ }^{6}$ For more on the relationship between socio-economic status and various health outcomes see Adler and Rehkopf (2008), Adler et al. (1994), Deaton (2001), Herd (2010), Matthews and Gallo (2011), and Wilkinson (1996).
} 
as adults for only a short time, although they may have participated as children. These arguments raise doubts about the potential magnitude of any effect of SNAP participation on aggregate obesity rates.

\section{Data}

We use data from the 2001-2002, 2003-2004, and 2005-2006 public-use NHANES, which were nationally representative cross-sectional surveys of the non-institutionalized US population. For brevity, we refer to these as the 2001-2006 NHANES. The NHANES contains details on characteristics of households and individuals, dietary recall information, lab test results, and

physical exam measurements. These detailed data enable us to estimate the relationship between SNAP participation and energy balance and to control for a wide variety of behavioral and health characteristics, including alcohol consumption, smoking, thyroid condition, breastfeeding, frequency of consuming food away from home, and depression. Moreover, unlike some previous studies, we use data on measured weight in addition to self-reported weight.

The National Center for Health Statistics (NCHS) and the Centers for Disease Control and Prevention (CDC) conduct the NHANES. Starting in 1999 the NHANES became a continuous annual survey with publicly available data released in two-year increments. The NHANES has a complex survey design and is intended to represent civilian noninstitutionalized individuals of all ages living in the United States. Of the 38,779 individuals screened for participation in the 2001-2006 NHANES, 31,509 completed interviews, and 30,070 underwent a physical exam in the mobile examination center. We use the sampling 
weights, masked variance units, and strata provided in the publicly available 2001-2006 NHANES data.7 Given that the previous literature finds no effect of participation on obesity in men, we restrict the data to non-pregnant women aged at least 18 and no older than 70 who had non-missing values for the variables used in our analysis, and household income no more than $185 \%$ of the federal poverty threshold. We choose women who had reported household income at or below $185 \%$ of the federal poverty threshold because this is the household-size-adjusted gross income cutoff for the Special Supplemental Nutrition Program for Women, Infants, and Children (WIC), and women who participate in SNAP automatically qualify to receive WIC benefits as well, i.e., they have "automatic eligibility." 8 This makes women at or below this cutoff reasonably representative of the eligible female population. 9

We have data on 2,592 women aged between 18 and 70 with household income no more than $185 \%$ of the federal poverty threshold, i.e., eligible for SNAP. After dropping missing observations, we are left with observations on 2,018 women, 514 of whom participated in SNAP ${ }^{10}{ }^{11}$ Appendix Table A2 describes all the variables used in the analysis.

[Table 1a. Summary Statistics for Low-Income Women-Public-Use NHANES Data]

\footnotetext{
${ }^{7}$ Using the "WTMEC2YR" survey weights we construct the appropriate weights for the six years of combined data with the formula (MEC6YR $=1 / 3 \times$ WTMEC2YR) and the tutorial provided by the National Center for Health Statistics (NCHS). We perform all analysis in Stata-MP 12.0 for Windows.

${ }^{8}$ See more at http://www.fns.usda.gov/wic/wic-eligibility-requirements.

${ }^{9}$ For thoroughness, we also estimated our models using SNAP gross income cut-off of $130 \%$ of poverty and the qualitative results did not change. See also footnote 16.

${ }^{10}$ For the 574 observations with missing data, the average weight difference between participants and nonparticipants was 14.1 pounds, compared with 15.5 pounds in our estimation sample.

${ }^{11}$ Previous research has documented extensive reporting error in surveys that assess participation in SNAP. However, the characteristics associated with non-reporting are not consistent across surveys or geographic regions (Meyer and George 2011). Kreider et al. (2012) present methods for addressing selection and misreporting bias in NHANES data, however we do not use these methods in this study. The estimated SNAP participant population in our data equals 23.9 million, which is reasonable considering administrative data reports 17.3-26.6 million participants between 2001 and 2006.
} 
Table 1a displays summary statistics for the public-use NHANES data described above. Consistent with Figure 1, SNAP participants weighed an average of 15.5 pounds more than eligible nonparticipants (referred to simply as "nonparticipants" below). Body weight is measured as part of the medical examination; in many other surveys, it is self-reported. In addition to measuring current weight, NHANES asks participants to estimate how much they weighed one year earlier. We use the difference between the measured current weight and the reported past weight to estimate the change in weight over the previous year, and find that participants gained 6.7 pounds on average compared with 4.9 pounds for nonparticipants. This difference is statistically insignificant at the $10 \%$ level.

Women tend to underestimate their current and past weight, and the severity of their underestimation increases with current BMI (Rowland 1990; Perry et al. 1995), so it is possible that this weight change (the difference between current measured weight and selfreported past weight) overestimates the actual weight gain. In addition, both men and women who have lost weight tend to underreport their past weight more than those who had maintained their weight or gained weight, implying that individuals underestimate losses more than they overestimate gains (Perry et al. 1995). The underreporting bias may be mitigated in the present case because survey respondents answered the question about past weight after having been weighed. Black, Taylor, and Coster (1998) found that the accuracy of self-reported weight did not decrease as weight increased for individuals who knew they would have their weight measured following the weight survey. Moreover, as long as SNAP participants are not more or less likely than nonparticipants to underreport past weight, we can still consistently estimate the difference in weight gain between the two groups.

Participants consume an estimated 40.2 more kilocalories (kcal) per day than non- 
participants. This estimate has a wide $95 \%$ confidence interval, from -66.4 to $146.7 \mathrm{kcal}$ per day. NHANES estimated food and energy consumption (dietary intake) using 24-hour dietary recall measurements 12 Dietary recall data are notorious for underreporting total energy intake (Briefel et al. 1997; Livingstone and Black 2003), but the difference in calorie consumption by participants and nonparticipants is not biased unless SNAP participants systematically underreport food consumption by more or less than do nonparticipants. Unfortunately, there are no methods currently available to account for the systematic biases in self-reported dietary intake (Archer, Hand, and Blair 2013). We have attempted to control for factors known to bias self-reported food intake, such as age and gender.

Compared with nonparticipants, participants were significantly less likely to engage in vigorous physical activity and expended an estimated 34.6 fewer calories in leisure-time physical activity per day; thus, the net difference in daily calorie intake between participants and nonparticipants is approximately 75 kcals. NHANES collected information on the frequency, duration, and intensity of several physical activities including walking, running, and biking during the past month. ${ }^{13}$

Table 1a shows numerous other differences between female participants and eligible

\footnotetext{
${ }^{12}$ The survey includes two separate dietary recall questionnaires conducted on different days. We use the average across the two days if two days were reported, and the one-day intake if the respondent reported intake for only one day.

${ }^{13}$ The intensity variable is reported in metabolic equivalents (METS), where a MET corresponds approximately to $0.9 \mathrm{kcal}$ per kilogram of bodyweight per hour for the average woman (Gropper, Smith and Groff, 2009 , p. 296). We combine this information to estimate daily calories expended in leisure-time physical activity. Specifically, we estimate the daily energy expenditure in leisure-time physical activity using the formula: $A C T=9.8 W \sum_{j}\left(\operatorname{METS}_{j}\left(t_{j} / 24\right)\left(f_{j} / 30\right)\right)$, where the subscript $j$ indicates the activity type, $t$ represents the length of time spent in the activity (in hours per event), $f$ measures the frequency of the activity over the previous month, and $W$ is weight in pounds. The constant 9.8 is the $\mathrm{kcal} /$ pound/day equivalent of $0.9 \mathrm{kcal} / \mathrm{kg} /$ hour. We assume zero activity for any missing entries for leisure-time physical activity. Troiano et al. (2008) found that self-reported measures of physical activity in NHANES 2003-2004 were qualitatively compatible with objective measures of activity gathered from accelerometers, in that women and older individuals engaged in less physical activity, but that individual reports significantly overstated the percentage of individuals who completed the recommended 30 minutes per day of moderate intensity physical activity.
} 
nonparticipants in characteristics associated with body weight. Compared with nonparticipants, participants in our sample are less likely to have a college education, less likely to be married, and more likely to have young children, although they are slightly younger. Black respondents make up $35 \%$ of participants but only $14 \%$ of nonparticipants. In contrast, Mexican-American respondents comprise only $9 \%$ of participants but $15 \%$ of nonparticipants 14 Participants are $9 \%$ more likely to be U.S. citizens. Participants are poorer on average; they have $36 \%$ lower average incomes (relative to the poverty line), are $51 \%$ more likely to rent their home, and eat 0.8 fewer meals per week away from home. These demographic and socioeconomic differences reveal that participants differ from nonparticipants in more than just weight and therefore that controlling for these characteristics is important in discerning the effects of participation on weight and weight gain.

Participating women also differ in their behavioral and health characteristics. Compared with nonparticipants, participants report having experienced approximately four more days of feeling depressed in the previous month, have a $20 \%$ greater probability of meeting the criteria for metabolic syndrome, consume nearly 10 more grams of sugar per day, drink 0.3 more alcoholic drinks per day, and have almost twice the propensity to smoke.15 Also, participants have a greater probability of sitting for most of the day and a lower probability of doing light lifting or climbing stairs on a daily basis. These differences all suggest that participants have less-healthy lifestyles and poorer health than nonparticipants, and may

\footnotetext{
${ }^{14}$ Low participation by Mexican-Americans may be influenced by immigrant eligibility requirements and other barriers to participation. See more at/http://www.fns.usda.gov/sites/default/files/ Non-Citizen_Guidance_063011.pdf.

${ }^{15}$ The National Cholesterol Education Program identifies individuals as having metabolic syndrome if they display three or more of the following five risk factors: (i) abdominal obesity (waist circumference $>102 \mathrm{~cm}$ for men or $>88 \mathrm{~cm}$ for women); (ii) elevated blood triglycerides $(\geq 150 \mathrm{mg} / \mathrm{dL})$; (iii) low HDL cholesterol $(<$ $40 \mathrm{mg} / \mathrm{dL}$ for men and $<50 \mathrm{mg} / \mathrm{dL}$ for women); (iv) hypertension ( $>130 / 85 \mathrm{mmHg}$ ); and (v) hyperglycemia (fasting blood glucose $\geq 110 \mathrm{mg} / \mathrm{dL}$ ).
} 
explain both their participation in SNAP and their heavier weight.

\section{Physiological Models of Weight Gain}

On a daily basis the amount of energy stored $(E S)$, or weight gained, depends on the amount energy consumed $(E C)$ relative to energy expended $(E E)$, as shown in the energy balance equation (Hill, Saris, and Levine 1998; Hill and Commerford 1996):

$$
E S=E C-E E
$$

Total energy expended has two main elements, (i) the resting metabolic rate (RMR), which is the amount of energy needed to sustain life for a human at rest, and (ii) energy expended during physical activity (ACT).$^{16}$ In addition to these main elements, humans also expend energy during digestion and in maintaining a normal body temperature (see, for example, Mifflin 1990; Frankenfield, Roth-Yousey, and Compher 2005; Henry 2005; Sherwood 2007; Gropper, Smith, and Groff 2009).

\subsection{Energy Requirements}

Based on a dynamic model of energy balance, Hall et al. (2011) estimate that a permanent increase in energy intake of $10 \mathrm{kcal}$ per day causes a 1 pound gain in steady-state weight. They estimate that weight increases by 0.5 pounds in the first year and reaches the steady

\footnotetext{
${ }^{16}$ Basal metabolic rate (BMR), resting metabolic rate (RMR), and resting energy expenditure (REE) are often used interchangeably, but BMR has specific measurement criteria. BMR is the amount of energy expended when a person is lying down in a thermo-neutral environment, not moving, has not eaten in 12 hours (i.e., "post absorptive"), and has recently awoken from a full-night sleep (Gropper, Smith and Groff 2009).
} 
state after approximately three years. Similarly, the parameterization in Christiansen et al. (2005) implies a steady-state increase of 1.28 pounds and a one-year increase of 0.77 pounds for each $10 \mathrm{kcal}$ per day increase in energy consumption. A detailed description of dynamic energy-balance models is provided in the Appendix. This dynamic process differs substantially from the popular notion that the change in weight is proportional to calorie intake and therefore that a permanent increase in the rate of caloric intake causes a permanent increase in the rate of weight gain.

Table 1a shows that SNAP participants weighed 15.5 pounds more than eligible nonparticipants during our 2001-06 sample period (see also Figure 1). How many additional calories per day would be required to sustain this weight difference? To begin, suppose this difference reflects a difference in steady-state weight resulting from several years of increased calorie intake. Under this supposition, the Christiansen et al. (2005) energy balance model implies that SNAP participants were consuming about 121 kcal per day more than nonparticipants, holding physical activity constant (see the Appendix for details). If SNAP participation causes weight gain and participants had not yet reached their steady-state weight (still gaining weight), then participants should have been consuming an amount greater than 121 kcal per day more than eligible nonparticipants to account for the 15.5 pound difference in body weight. To put this in context, $121 \mathrm{kcal}$ is roughly equivalent to the energy in one large banana and less than that in a 12 oz can of cola. 17 Table 1a shows that participants consumed $40 \mathrm{kcal}$ more and expended $35 \mathrm{kcal}$ less energy per day than nonparticipants. This net difference of $75 \mathrm{kcal}$ per day is too small to explain all of the observed average weight

\footnotetext{
${ }^{17}$ The model of Hall et al. (2011) requires an even greater food-intake difference of $155 \mathrm{kcal}$ per day to generate 15.5 additional pounds of weight. By focusing on the Christiansen et al. (2005) model we set a lower threshold for the energy differences required to explain the weight gap (see Table 1b).
} 
difference, though it could plausibly account for a significant share of the difference.

Women would need to participate in the program for an extended period of time for this net difference to have an impact on body weight. However, most SNAP spells are less than one year (Cody et al. 2005; Cody et al. 2007; Mabli et al. 2011). In our data, we categorize SNAP participants as those who participated for at least one month during the past year. These participants make use of the program for 7.6 months on average, which is very similar to the eight-month median participation spell reported by Cody et al. (2007). If participation leads to increased food and energy consumption only in the months during which a person participates, then the additional calorie consumption for current participants would need to be substantially greater than 121 kcal per day. The above models suggest that the expected weight gain would be a little over half of the steady-state gain after one year of increased food and energy consumption, and less than half of the steady-state gain after only 7.6 months of increased energy consumption. These arguments suggest that the additional energy consumption of participants - while participating — would need to be substantially more than $121 \mathrm{kcal}$ per day before increased energy consumption caused by SNAP participation could explain the weight gap.18

This analysis shows that average differences in food consumption and physical activity are insufficient to account for all, or even most of the average weight difference between SNAP participants and nonparticipants. However, these averages may obscure important heterogeneity between participants and nonparticipants with respect to age, race, and other

\footnotetext{
${ }^{18}$ If some of the participants in our sample were repeat SNAP participants, with a total continuous spell length of 18 months or more and a sustained increase in net caloric intake of $75 \mathrm{kcals}$ per day, we would expect a 9.6 pound difference in steady-state weight for these participants. Recall however that, during the 36 month period 2004-2006, $60 \%$ of households had a median total spell length of 18 months and a median time-off between spells of 20 months (Mabli et al. 2011).
} 
exogenous characteristics, or with respect to behavioral characteristics like alcohol consumption, education, and smoking. In the next section, we use regression models to ask whether SNAP participation is associated with increased calorie consumption and reduced physical activity after controlling for demographic, socioeconomic, behavioral, and health characteristics.

\subsection{Does SNAP Participation Affect Energy Balance?}

The natural channel for SNAP participation to affect weight is through energy consumption $(E C)$ or physical activity $(A C T)$. To explore these possibilities, we estimate the following regression equations:

$$
\begin{gathered}
E C=\delta_{0}+\delta_{1} S N A P+\delta_{2} \mathbf{Z}+\varepsilon_{E C}, \\
A C T=\beta_{0}+\beta_{1} S N A P+\beta_{2} \mathbf{Z}+\varepsilon_{A C T} .
\end{gathered}
$$

The vector $\mathbf{Z}$ includes information on age, race, socio-economic status (marital status, income-to-poverty ratio, and educational attainment), health behaviors and conditions (smoking, alcohol, thyroid conditions, depression, serum C-reactive protein, television and computer viewing time, and the number of meals at restaurants), and employment characteristics (indicators for being employed, ever-worked, and working full-time). Tables 2 and 3 contain the results from ordinary least squares (OLS) estimation of the models in equations (2) and (3). The results imply that SNAP participants do not differ significantly from eligible nonparticipants in energy consumed or energy expended in leisure-time physical activity.

[Table 2. OLS Regression of Calorie Intake on SNAP Participation] 
In column 1 of Table 2, the coefficient on "SNAP last year" shows that SNAP participants consumed 40.2 calories per day more than eligible nonparticipants did, although this difference is statistically insignificant. After controlling for age and race, in column 3 the coefficient becomes -7.9 ; this value is small, negative, and statistically insignificant. The magnitude remains similar when we introduce other controls. Thus, not only is the average difference in calorie consumption too small to explain the weight gap, it is better explained by demographic differences than by SNAP participation. In particular, black women report consuming 117 more calories than white women; as Table 1a shows, a relatively high proportion of black women are SNAP participants and a comparatively high proportion of SNAP participants are black.

The results are similar if we measure participation by the number months participating during the past year rather than a dummy variable indicating participation at some point during the year. In columns 4, 6 , and 8 of Table 2, the negative coefficient on SNAP spelllength contradicts the expectation that a relatively longer SNAP participation spell would result in greater caloric consumption and thus a relative weight gain. This lends further credence to the claim that SNAP participation does not cause weight gain by causing food consumption to increase ${ }^{19}$

We include controls for health behavior and characteristics known to affect body weight and energy consumption. Few of the coefficients on the control variables are individually statistically significant in the calorie regression, however they are jointly significant at the $1 \%$ level ${ }_{[20}^{20}$ Calorie consumption decreases with age. All else equal, a 40 year old is predicted

\footnotetext{
${ }^{19}$ When we restrict the sample to women with income less than $130 \%$ of the federal poverty line the estimated coefficient on SNAP participation in the previous year in equations (2) and (3) is larger in magnitude but statistically insignificant.

${ }^{20}$ Omitting the "needs more support," "having a thyroid condition," "C-reactive protein," and "monthly
} 
to consume about 130 kcals per day less than a 20 year old and about 200 kcals per day more than a 60 year old. These declines reflect declines in the RMR as people age. Estimated weight one year previously is negatively related to calories consumed, although the coefficient is statistically and physiologically insignificant. One possible explanation for the negative coefficient on past weight is that heavier individuals may have made attempts to lose weight by decreasing their energy consumption (Briefel et al. 1997).

As discussed in Section 3, the propensity to underreport energy consumption increases with weight. Black (2000) and Livingstone and Black (2003) suggest estimating the propensity to misreport food intake by classifying as under-reporters those individuals who report low energy consumption relative to their resting metabolic rate (EC/RMR). Based on this method, a greater propensity to report low EC/RMR by SNAP participants would indicate that they are more likely to underreport food and energy consumption. However, a low reported ratio could be accurate if the woman was losing weight or was sedentary, or if the survey was taken on a day when she ate much less than usual.

To address this possibility, we categorize as under-reporters those women who have EC/RMR below their self-reported average amount of daily physical activity, and check whether SNAP participants are more likely than nonparticipants to be under-reporters.21 We do not find a significant difference in underreporting for participants versus nonparticipants (61\% versus $56 \%$ probability, respectively). Thus, we have some evidence to suggest that systematic bias in the dietary recall data for SNAP participants does not account for the observed differences in weight and energy consumption.

days of depression" variables minimally changes the coefficient on SNAP participation to $23.2 \mathrm{kcal} /$ day, but it remains statistically insignificant.

${ }^{21}$ From appendix equation (A2), women with normal activity levels have EC/RMR approximately equal to 1.5 . 
[Table 3. OLS Regression of Energy Expended in Physical Activity on SNAP

$$
\text { Participation] }
$$

Table 3 shows that SNAP participation is associated with a smaller amount of energy expended in leisure-time physical activity (17 kcals per day less in the full specification), but the difference becomes smaller in magnitude and insignificant after introducing controls such as smoking and having a child under one year of age, both of which are positively associated with SNAP participation (see Table 1a). Table 3 also shows that the amount of energy expended in leisure-time physical activity declines as women age. Women who smoke or are married expend about 43 and 61 kcals per day less, respectively, but heavy television watchers do not expend significantly less energy. The results are similar if we represent participation by the number of months of participating during the past year rather than by a dummy variable indicating participation at some point during the year, where each additional month of participation is associated with a statistically insignificant 2.4 kcal decrease in energy expenditure.

The results in Tables 2 and 3 show that differences in energy balance are insufficient to explain more than a small fraction of the greater weight of SNAP participants compared with nonparticipants. Using the regression coefficients from column 7 of each table, the results suggest a net effect of an additional 38.5 kilocalories $(=21.5+17)$ for SNAP participants in comparison to non-participants. This is both a statistically and physiologically insignificant difference, and approximately one-third of the minimum excess kilocalories per day needed to explain the 15.5 pound difference in body weight.

These results leave three possibilities that we explore in the remainder of the paper. 
First, SNAP participation may cause a small energy imbalance that is obscured by systematic measurement error in our measures of food intake and physical activity. It would stretch credibility to claim that measurement error differences between participants and nonparticipants could be large enough to explain the entire 15.5 pound weight difference, but the above analysis does not rule out the possibility that SNAP participation causes some weight gain.

Second, SNAP participation may change dietary composition in ways that do not affect energy balance, but which change RMR or physical activity in ways that the simple energy balance model does not capture. For example, if SNAP leads people to a diet high in refined carbohydrates (e.g., white sugar and flour), resulting in a chronic state of hyperinsulinemia (high blood insulin), increased fat deposition, and decreased physical activity, then RMR could decline causing weight to increase even if energy consumption had not changed (Kahn and Flier 2000; Taubes 2008; Wells and Siervo 2011). The evidence on differences in diet quality between SNAP participants and income-eligible non participants does not support this hypothesis (Andreyeva, Tripp, and Schwartz 2015), and as we show below, we do not find that participants were gaining weight.

Third, differences in RMR across individuals may be correlated both with the propensity to be heavy and the propensity to participate in SNAP. In other words, the association between being heavy and participating in SNAP is an example of omitted variables bias. We address the first two possibilities in Section 5 and the third possibility in Section 6 . 


\section{Regression Models of Weight Gain}

With a few exceptions, previous studies modeled the cross-sectional relationship between body weight or body mass index (BMI) and participation in SNAP. However, a consideration of the structural relationships, in the biological or physiological sense, suggests that we should be modeling the relationship between participation in SNAP and changes in weight. We begin with the reduced-form regression model

$$
\Delta W=\alpha_{0}+\alpha_{1} S N A P+\alpha_{2} \mathbf{Z}+\varepsilon_{\Delta W}
$$

where the control variables, $\mathbf{Z}$ control for heterogeneity in base energy expenditure $(\overline{R M R})$. We include in $\mathbf{Z}$ individual characteristics that reflect genetic (e.g., race), physiological (e.g., having a thyroid condition), and behavioral (e.g., television viewing time) determinants of body weight, in addition to several measures of socio-economic status suggested in the literature (Feinman and Lieber 1998; Rooney and Schauberger 2002; Chiolero et al. 2008; Kim 2008; Clark and Dillon 2011; Fraser et al. 2011; Hall, Hammond, and Rahmandad 2014). Many of these individual characteristics have not been controlled for in previous papers on this topic. We use the same two measures of SNAP participation as in the models reported in Tables 2 and 3.

A growing vein of medical literature suggests that the simple energy balance equation (i.e., comparing energy intake and expenditure) does not entirely explain why some people continuously gain weight and never reach a weight plateau (see Wells and Siervo 2011 and references therein). To estimate whether factors beyond energy balance can explain the correlation between SNAP participation and body weight, we augment (4) with measures of 
calorie surplus and physical activity. The model is:

$$
\Delta W=\alpha_{0}+\alpha_{1} S N A P+\alpha_{2} \mathbf{Z}+\alpha_{3} C S+\alpha_{4} A C T+\varepsilon_{\Delta W}
$$

where $A C T$ is the activity variable from equation (3), $C S=E C-0.9 \times 24 \times(1 / 2.204) W_{0}=$ $E C-9.8 W_{0}$ denotes the calorie surplus, and $W_{0}$ denotes the current weight.22 Calorie surplus equals calories consumed in excess of those required to maintain current weight for no leisure-time physical activity $(A C T=0)$ and at the benchmark resting metabolic rate $\overline{R M R}$. (See appendix equation (A2) and Gropper, Smith and Groff 2009). In (5), the coefficient on SNAP participation captures any relationship between SNAP and weight gain holding activity and calorie surplus constant.

Table 4 displays the results from estimation of the model described by equations (4) and (5) for low-income women. Columns 1, 3, 5, and 7 display the results of the models in (4) and (5), adding progressively more individual characteristics. The coefficient on SNAP participation is statistically insignificant in each case. Including the activity $(A C T)$ and calorie surplus $(C S)$ variables has little effect on the estimated coefficient on SNAP participation (columns 5 and 7 in Table 4). This has implications for the interpretation. If we were to assume that SNAP coefficient in Table 4 represents a causal effect of the program, and that this effect worked through a change in energy balance, then we would expect controlling for calorie surplus to reduce the coefficient on SNAP. However, this did not happen, which is consistent with the results in Tables 2 and 3, indicating that SNAP participation does not

\footnotetext{
${ }^{22}$ We also tried several other RMR prediction equations including the Mifflin St. Jeor, Oxford, and $\mathrm{WHO} / \mathrm{FAO} / \mathrm{UNU} /$ Schofield prediction equations. The results were qualitatively the same and are available upon request. We did not use RMR prediction equations based on FFM and FM because we observe these variables only for a subset of our sample. Frankenfield, Roth-Yousy, and Compher (2005) found that the Mifflin St. Jeor equation predicted RMR with less error than the Harris-Benedict, WHO/FAO/UNU/Schofield, or Owen RMR prediction equations. Henry (2005) found that the WHO/FAO/UNU/Schofield equation often over-estimates RMR, and presented the new Oxford RMR equations.
} 
cause weight gain by changing energy balance.

We find even weaker evidence that SNAP is associated with weight gain when we use SNAP spell-length (measured in months); see columns 2, 4, 6, and 8 of Table 4 . Without any controls, we obtain an insignificant coefficient estimate of 0.085 pounds of weight gain per month of participation in SNAP; this estimate becomes negative when we add controls to the model, but it remains statistically insignificant with a $95 \%$ confidence interval of $(-0.37,0.26)$ in column 8. Thus, taking the point estimates at face value, additional months on SNAP are associated with a small weight loss.23 We also explored the relationship between "longterm" participation ( $\geq 8$ months) and again found a statistically and clinically insignificant relationship between SNAP participation and weight gain over the previous year (results not shown).

As we would expect, a significant positive relationship exists between calorie surplus and weight gain. The coefficients on calorie surplus are about 0.0037 , which suggests that a calorie surplus of $100 \mathrm{kcal}$ per day is associated with a 0.37 pound increase in body weight over a full year, much less than the 7 pounds implied by the physiological model in equation (A6) or the 5 pounds implied by the model in Hall et al. (2011). However, these models hold physical activity constant. Hall et al. (2009) suggest the formula $\Delta W_{l b s}=$ $0.047 \times \Delta C S_{k c a l}$ i.e., a coefficient of 0.047 . Our smaller estimate may reflect measurement error in our variables representing intake of calories and leisure-time physical activity ${ }^{24}$

\footnotetext{
${ }^{23}$ When we restrict the data set to include only women for whom we have information on occupation and employment, and include indicators for occupation class and whether they worked outside the home, the coefficient on SNAP participation decreases to 0.33 (results not shown). Women with a job categorized as "manufacturing," which likely entails more strenuous activity than occupations in the retail, healthcare, or transportation categories, gained less weight.

${ }^{24}$ Classical measurement error would bias the coefficient on $C S$ towards zero, but would not bias the regressions in Table 3, in which calorie consumption is the dependent variable.
} 
Few of the coefficients on individual control variables in Table 4 are statistically significant. Women who reported that they were breastfeeding gained almost 7 more pounds in the past year than women who did not breastfeed at the time of the survey (because they had not recently given birth or were formula feeding their infants). Being married, having a thyroid condition, higher amounts of C-reactive protein in the blood, and spending more than three hours a day on the computer are also associated with having gained more weight over the past year.

[Table 4. OLS Regression of Change in Weight on SNAP Participation]

We conducted several robustness checks of our results. Following Shapiro (2005) and using data from the 2007-2008 NHANES we also investigated whether the timing of the disbursement of SNAP benefits was associated with a difference in caloric intake, and found none ${ }^{25}$ In addition, the qualitative results were unchanged when we conducted the analysis without survey weights, or dropped observations with extreme values for calorie intake.

In summary, after exploring several specifications and accounting for the duration of participation, we find no convincing evidence that participation in SNAP causes weight gain.

\section{Explaining Participation in SNAP}

The regression models presented in this paper and the related literature take obesity or weight gain as a variable to be explained and SNAP participation as a potential explanatory variable. Our results provide no support for the hypothesis that SNAP participation causes weight gain, so we are left with the conclusion that SNAP participants differ from eligible

\footnotetext{
${ }^{25}$ These results are omitted for brevity, but are available upon request.
} 
nonparticipants in ways that are correlated with weight. Phrased this way, the relevant variable to be explained is SNAP participation, i.e., investigating what causes SNAP participation may be a more fruitful line of research for understanding its positive correlation with obesity. Thus, we develop a model of program participation in which body weight can influence the choice to participate in SNAP.

Chronic poverty could promote both weight gain and SNAP participation. If poor individuals have myopic or present-biased preferences they will be less willing to forgo pleasure in the current period (e.g., cutting back on ice cream) to ensure benefits in later periods (e.g., maintaining healthy body weight) (Komlos, Smith, and Bogin 2004; Smith, Bogin, and Bishai 2005). The experience of living in poverty and in impoverished areas can affect individual decision-making and preferences, and may therefore influence participation in SNAP because relatively disadvantaged people have greater potential benefits from, and possibly willingness to use, social assistance programs (Harding, Lamont, and Small 2010, p. 11). Chronic stress and socioeconomic disadvantage have been shown to increase the risk of several diseases by consistently triggering the stress response system, which disrupts normal bodily functions such as metabolism (Adler et al. 1994; American Psychological Association 2015; Pearlin et al. 2005).

Alternately, obese individuals may have a greater willingness-to-pay for food than nonobese individuals because they find it more rewarding or enjoyable, and they may also have greater willingness to pay the stigma and transactions costs of applying for and using SNAP benefits (Saelens and Epstein 1996).

Following Moffitt (1983) and Meyerhoefer and Pylypchuk (2008), we model the decision to participate in SNAP by an income-eligible household as the result of a household utility 
maximization process. Equation (6) represents the empirical counterpart of the conceptual model of SNAP participation described by equation (7) of Meyerhoefer and Pylypchuk (2008).

$$
S N A P=\phi_{0}+\phi_{1} W+\phi_{0} \mathbf{Z}+\varepsilon_{S N A P}
$$

In equation (6), SNAP is a binary indicator of participation in the previous 12 months. In addition to the variables used as controls in equations (3)-(5), the vector $\mathbf{Z}$ also includes an indicator for U.S. citizenship, the number of months at the current job, and home-ownership status.

Because access to SNAP varies geographically, we also use restricted-use data, available only through a National Center for Health Statistics or Census Research Data Center, on the state and county where the survey respondent resides ${ }^{26}$ This geographic information allows us to include additional variables in the analysis. We use county unemployment rates for years 1999 through 2006 from the US Bureau of Labor Statistics. ${ }^{27}$ We also extracted from the US Census Bureau's Local Area Unemployment Statistics series, data on (i) the percentage of the total population living at or below the federal poverty line, (ii) the percentage of the population 0 to 17 years old living at or below the poverty line, and (iii) median family income by county ${ }^{28}$ From the USDA ERS we use information and variables from the Food

\footnotetext{
${ }^{26}$ We applied the sampling weights, masked variance units, and strata provided in the publicly available 2001-2002, 2003-2004, and 2005-2006 NHANES data, and performed all analysis in Stata-MP 12.0 at the Census Research Data Center in Berkeley, CA. Using the same criteria outlined above to limit the NHANES data and dropping observations with missing county characteristics, SNAP characteristics, or geographic identifiers, 2,375 observations remained (497 participants and 1,878 nonparticipants). The 2,375 observations in the sample have a survey-weighted mean body weight of 178.5 pounds (with a standard error of 2.6) for SNAP participants and 163.9 pounds (with a standard error of 1.2 ) for nonparticipants.

${ }^{27}$ Available at: http://www.bls.gov/lau/tables

${ }^{28}$ Available at: http://www.census.gov/did/www/saipe/data/statecounty/data/index.html and http://www.census.gov/popest/eval-estimates/eval-est2010.html
} 
Environment Atlas and the Rural-Urban Continuum Codes ${ }^{29}$ The USDA FNS provided us with an unreleased and updated version of the Food Stamp Program Rules Database, which contains information on state-specific SNAP rules governing asset limits, length of the re-certification period, immigrant eligibility, issuance methods, reporting requirements, and outreach activities.

\section{[Table 5. OLS Model of SNAP Participation]}

Table 5 contains the results for equation (6) estimated by OLS. Column 1 shows that the probability of SNAP participation increases by 0.001 for every pound of body weight. This coefficient provides another way to view the differences in body weight shown in Figure 1. If this significant coefficient reflects omitted-variables bias, then including those omitted variables in the model would reduce the coefficient on body weight to zero. When we control for age and race, the coefficient drops by $10 \%$ to 0.0009 , and its value remains nearly the same when we add a long list of individual, county, and state characteristics, and state fixed effects.

The inclusion of additional determinants of SNAP participation does not make the relationship between current weight and participation insignificant. The coefficient in column 4 implies that for two women with a 20 pound difference in body weight, the heavier woman has a 1.6 percentage point (or $7.6 \%$ ) greater likelihood of choosing to participate in SNAP than the lighter woman, all else equal.

The full specification in column 4 of Table 5 provides further insight into the many individual and household characteristics that are associated with the decision to participate

${ }^{29}$ Available at: http://www.ers.usda.gov/foodatlas/ and http://www.ers.usda.gov/data/
ruralurbancontinuumcodes/.


in SNAP. As in previous studies, we find that women have a lower probability of participating in SNAP if they are older, married, educated, and have relatively high income. Conversely, we find that women have a higher probability of participating in SNAP, all else equal, if they are from racial or ethnic minorities, rent their homes, smoke cigarettes, or have infants and young children (between one and five years old). Women currently breastfeeding their infants have a significantly lower probability of participating in SNAP.

As did Wilde, Troy, and Rogers (2009) and Pan and Jensen (2008), we also found evidence that individuals who eat a greater number of meals away from home - which may signify a stronger preference for food away from home - have a lower probability of participating in SNAP. All else equal, and as we might expect, women who lived in states that applied a sales tax to food items (i.e., had relatively higher food costs for food purchased with cash income rather than SNAP benefits) had a higher probability of participating in SNAP ${ }^{30}$ Lastly, several state fixed effects significantly increased or decreased the likelihood that women participated in SNAP ${ }^{31}$

\section{Conclusion}

Many commentators and some policymakers have suggested that SNAP may have contributed to the "obesity epidemic" by facilitating the overconsumption of food and calories. In response to these concerns, researchers have attempted to model and measure the effects of SNAP participation on obesity in the United States. However, it has proved very dif-

\footnotetext{
${ }^{30} \mathrm{By}$ federal law, sales tax may not be charged on food purchased with SNAP benefits. If a food or beverage item is ordinarily subject to sales tax, the purchase will be nontaxable if the item is purchased with SNAP benefits.

${ }^{31}$ The state identifiers were included in the restricted use data and de-identified. Thus, we cannot say which states had significantly different participation, only that some did.
} 
ficult to identify a causal relationship between SNAP participation and obesity. Much of the previously published work on the subject has failed to: (i) adequately control for the systematic differences between SNAP participants and nonparticipants (i.e., selection bias), (ii) test whether SNAP participation is associated with increased weight gain, and (iii) consider the possibility that, along with many other individual and household characteristics, body weight also affects the decision to participate in SNAP. These gaps in the literature motivated this study.

Identifying a causal link between SNAP participation and weight gain is difficult, in part because the decision to participate in SNAP is likely to depend on many factors that researchers will never observe. We use the NHANES dataset, which contains detailed information on a wide variety of demographic, socioeconomic, health and behavioral characteristics for 2,018 SNAP-eligible women. We emphasize the physiological mechanisms through which SNAP participation could affect weight. In particular, we relate changes in weight to SNAP participation while controlling for many of the individual and environmental characteristics and factors that influence the body weight of an individual.

SNAP provides a valuable safety net against hunger and malnutrition for millions of low-income Americans, and the existing literature has shown that SNAP achieves the goal of reducing food insecurity and preventing hunger (Gundersen, Kreider, and Pepper 2011). We explore the various links that might account for the observed correlation between weight and SNAP participation. The separate elements provide reinforcing evidence. We find no justification for making changes to SNAP on the grounds that SNAP participation causes weight gain. 


\section{References}

Adler, N. E., Boyce, T., Chesney, M. A., Cohen, A., Folkman, S., Kahn, R. L., \& Syme, S. L. (1994). Socioeconomic Status and Health: The Challenge of the Gradient. American Psychologist, 49(1), 15-24.

Adler, N. E., \& Rehkopf, D. H. (2008). U.S. Disparities in Health: Descriptions, Causes, and Mechanisms. Annual Review of Public Health, 29, 235-252.

American Diabetes Association. (2008). Economic Costs of Diabetes in the U.S. in 2007. Diabetes Care, 31(3), 596-615.

American Psychological Association. (2015). Fact Sheet: Health Disparities and Stress Retrieved April 28, 2015, from http://www.apa.org/topics/health-disparities/ stress.pdf

Andreyeva, T., Tripp, A. S., \& Schwartz, M. B. (2015). Dietary Quality of Americans by Supplemental Nutrition Assistance Program Participation Status: A Systematic Review. American Journal of Preventive Medicine, 49(4), 594-604.

Archer, E., Hand, G. A., \& Blair, S. N. (2013). Validity of US Nutritional Surveillance: National Health and Nutrition Examination Survey Caloric Energy Intake Data, 19712010. PLoS ONE, 8(10), e76632.

Baum, C. (2007). The Effects of Food Stamps on Obesity Report from the Economic Research Service: United States Department of Agriculture, Economic Research Service.

Baum, C. L., \& Ford, W. F. (2004). The Wage Effects of Obesity: A Longitudinal Study. Health Economics, 13, 885-899.

Black, A. (2000). Critical Evaluation of Energy Intake Using the Goldberg Cut-Off for Energy Intake:Basal Metobolic Rate. A Practical Guide to it's Calculation, Use and Limitations. International Journal of Obesity, 24, 1119-1130.

Black, D. R., Taylor, A. M., \& Coster, D. C. (1998). Accuracy of Self-Reported Body Weight: Stepped Approach Model Component Assessment. Health Education Research: Theory \& Practice, 13(2), 301-307.

Briefel, R., Sempos, C., McDowell, M., Chien, S. C.-Y., \& Alaimo, K. (1997). Dietary Methods Research in the Third National Health and Nutrition Survey: Underreporting of Energy Intake. American Journal of Clinical Nutrition, 65(Suppl), 1203S-1209S.

Cawley, J. (2004). The Impact of Obesity on Wages. The Journal of Human Resources, $39(2), 451-474$.

Chen, Z., Yen, S. T., \& Eastwood, D. B. (2005). Effects of Food Stamp Participation on Body Weight and Obesity. American Journal of Agricultural Economics, 87(5), 1167-1173.

Chiolero, A., Faeh, D., Paccaud, F., \& Cornuz, J. (2008). Consequences of Smoking for Body Weight, Body Fat Distribution, and Insulin Resistance. American Journal of Clinical Nutrition, 87(4), 801-809.

Chow, C. C., \& Hall, K. D. (2008). The Dynamics of Human Body Weight Change. PloS 
Computational Biology, 4(4), 1-11.

Christiansen, E., Garby, L., \& Sørensen, T. I. A. (2005). Quantitative Analysis of the Energy Requirements for Development of Obesity. Journal of Theoretical Biology, 234, 99-106.

Clark, M. K., \& Dillon, J. S. (2011). BMI Misclassification, Leptin, C-Reactive Protein, and Interleukin-6 in Young Women with Differing Levels of Lean and Fat Mass. Obesity Research 85 Clinical Practice, 5(2), e85-e92.

Cody, S., Castner, L., Mabli, J., \& Sykes, J. (2007). Dynamics of Food Stamp Program Participation, 2001-2003. Alexandria, VA: USDA, Food and Nutrition Service Office of Research, Nutrition and Analysis.

Cody, S., Gleason, P., Schechter, B., Satake, M., \& Sykes, J. (2005). Food Stamp Program Entry and Exit: An Analysis of Participation Trends in the 1990s. Mathematica Policy Research, Inc.: Economic Research Service, USDA.

Colditz, G. A. (1992). Economic Costs of Obesity. American Journal of Clinical Nutrition, $55,503 \mathrm{~s}-507 \mathrm{~s}$.

Deaton, A. (2001). Relative Deprivation, Inequality, and Mortality. NBER Working Paper Series No. 8099. NBER. Retrieved from: http://www.nber.org/papers/w8099

Devaney, B., \& Moffitt, R. (1991). Dietary Effects of the Food Stamp Program. American Journal of Agricultural Economics, 73(1), 202-211.

Drewnowski, A., \& Specter, S. E. (2004). Poverty and Obesity: The Role of Energy Density and Energy Costs. American Journal of Clinical Nutrition, 79, 6-16.

Fan, M. (2010). Do Food Stamps Contribute to Obesity in Low-Income Women? Evidence from the National Longitudinal Survey of Youth 1979. American Journal of Agricultural Economics, 92(4), 1165-1180.

Feinman, L., \& Lieber, C. S. (1998). Nutrition in Diet and Alcoholism. In M. E. Shils, J. A. Olson, M. Shike \& A. C. Ross (Eds.), Modern Nutrition in Health and Disease (9 ed., pp. 1395-1418). Baltimore, Maryland: Williams \& Wilkins.

Flegal, K. M., Graubard, B. I., WIlliamson, D. F., \& Gail, M. H. (2007). Cause-Specific Excess Deaths Associated with Underweight, Overweight, and Obesity. Journal of the American Medical Association, 298(17), 2028-2037.

Flegal, K. M., Carroll M. D., Kuczmarski, R. J., \& Johnson, C. L. (1998). Overweight and Obesity in the United States: Prevalence and Trends, 1960-1994. International Journal of Obesity, 22, 39-47.

Frankenfield, D. C., Roth-Yousey, L., \& Compher, C. (2005). Comparison of Predictive Equations for Resting Metabolic Rate in Healthy Nonobese and Obese Adults: A Systematic Review. Journal of the American Dietetic Association, 105(5), 775-789.

Fraser, A., Tilling, K., Macdonald-Wallis, C., Hughes, R., Sattar, N., Nelson, S. M., \& Lawlor, D. A. (2011). Associations of Gestational Weight Gain with Maternal Body Mass Index, Waist Circumference, and Blood Pressure Measured 16 y After Pregnancy: the Avon Longitudinal Study of Parents and Children. American Journal of Clinical 
Nutrition, 93(6), 1285-1292.

Gibson, D. (2003). Food Stamp Program Participation is Positively Related to Obesity in Low Income Women. Journal of Nutrition, 133, 2225-2231.

Gropper, S. S., Smith, J. L., \& Groff, J. L. (Eds.). (2009). Advanced Nutrition and Human Metabolism (5th ed.). Belmont, CA: WADSWORTH.

Gundersen, C., Kreider, B., \& Pepper, J. (2011). The Economics of Food Insecurity in the United States. Applied Economic Perspectives and Policy, 33(3), 281-303.

Hall, K. D., Hammond, R. A., \& Rahmandad, H. (2014). Dynamic Interplay Among Homeostatic, Hedonic, and Cognitive Feedback Circuits Regulating Body Weight. American Journal of Public Health 104(7), 1169-1175.

Hall, K. D., Guo, J., Dore, M., \& Chow, C. C. (2009). The Progressive Increase of Food Waste in America and Its Environmental Impact. PLoS ONE, 4(11), e7940.

Hall, K. D., Sacks, G., Chandramohan, D., Chow, C. C., Wang, Y. C., Gortmaker, S. L., \& Swinburn, B. A. (2011). Quantification of the Effect of Energy Imbalance on Bodyweight. The Lancet, 378(9793), 826-837.

Harding, D., Lamont, M., \& Small, M. L. (2010). Reconsidering Culture and Poverty (Vol. 629): SAGE.

Harris, J. A., \& Benedict, F. G. (1919). A Biometric Study of Basal Metabolism in Man. Carnegie Institute.

Henry, C. (2005). Basal Metabolic Rate Studies in Humans: Measurement and Development of New Equations. Public Health Nutrition, 8(7A), 1133-1152.

Herd, P. (2010). Education and Health in Late-Life among High School Graduates: Cognitive versus Psychological Aspects of Human Capital. Journal of Health and Social Behavior 51, 478-496.

Hill, J., Saris, W., \& Levine, J. (1998). Energy Expenditure in Physical Activity. Handbook of Obesity, 457-474.

Hill, J. O., \& Commerford, R. (1996). Physical Activity, Fat Balance, and Energy Balance. International Journal of Sport Nutrition, 6(2), 80-92.

Huang, E. S., Basu, A., O'Grady, M., \& Capretta, J. C. (2009). Projecting the Future Diabetes Population Size and Related Costs for the U.S. Diabetes Care, 32(12), 22252229.

Imbens, G. W., \& Wooldridge, J. M. (2009). Recent developments in the Econometrics of Program Evaluation. Journal of Economic Literature, 47(1), 5-86.

Jensen, H. H., \& Wilde, P. (2010). More Than Just Food: The Diverse Effects of Food Assistance. Choices: The Magazine of Food, Farm and Resource Issues, 25(3).

Kaushal, N. (2007). Do Food Stamps Cause Obesity? Evidence from Immigrant Experience. Journal of Health Economics, 26, 968-991.

Khan, B. B., \& Flier, J. S. (2000). Obesity and Insulin Resistance. Journal of Clinical Investigation, 106(4), 473-481. 
Kim, B. (2008). Thyroid Hormone as a Determinant of Energy Expenditure and the Metabolic Rate. Thyroid, 18(2), 141-143.

Komlos, J., Smith, P.K., \& Bogin, B. (2004). Obesity and the Rate of Time Preference: Is There a Connection? Journal of Biosocial Science, 36(02), 209-219.

Kreider, B., Gundersen, C., Pepper, J., \& Jolliffe, D. (2012). Identifying the Effects of Food Stamps on Child Health Outcomes When Participation is Endogenous and Misreported. Journal of the American Statistical Association, 107(499), 958-975.

Lakdawalla, D., \& Philipson, T. (2002). The Growth of Obesity and Technological Change: A Theoretical and Empirical Examination. NBER Working Paper Series.

Levi, J., Vinter, S., Laurent, R. S., \& Segal, L. M. (2010). F as in Fat: 2010: Robert Wood Johnson Foundation Trust for America's Health.

Livingstone, M., \& Black, A. (2003). Markers of the Validity of Reported Energy Intake. The Journal of Nutrition, 133(Suppl), 895S-920S.

Mabli, J., Tordella, S., Castner, L., Godfrey, T., \& Foran, P. (2011). Dynamics of Supplemental Nutrition Assistance Program Participation in the Mid-2000s (F. P. A. Branch, Trans.). Alexandria, VA: USDA Food and Nutrition Service.

Matthews, K. A., \& Gallo, L. C. (2011). Psychological Perspectives on Pathways Linking Socioeconomic Status and Physical Health. Annual Review of Psychology 62(1), 501-530.

Meyer, B. D., \& Goerge, R. M. (2011). Errors in Survey reporting and Imputation and Their Effects on Estimates of Food Stamp Program Participation. Center for Economic Studies Research Paper. U.S. Census Bureau. Washington, DC.

Meyerhoefer, C. D., \& Pylypchuk, Y. (2008). Does Participation in the Food Stamp Program Increase the Prevalence of Obesity and Health Care Spending? American Journal of Agricultural Economics, 90(2), 287-305.

Mifflin, M. D., Jeor, S. T. S., Hill, L. A., Scott, B. J., Daugherty, S. A., \& Koh, Y. O. (1990). A New Predictive Equation for Resting Energy Expenditure in Healthy Individuals. American Journal of Clinical Nutrition, 51, 241-247.

Moffitt, R. (1983). An Economic Model of Welfare Stigma. American Economic Review, 73(5), 1023-1035.

Nonnemaker, J., Finkelstein, E., Engelen, M., Hoerger, T., \& Farrelly, M. (2009). Have Efforts to Reduce Smoking Really Contributed to the Obesity Epidemic? Economic Inquiry, 47(2), 366-376.

Pan, S., \& Jensen, H. H. (2008). Does the Food Stamp Program Affect Food Security Status and the Composition of Food Expenditures? Journal of Agricultural and Applied Economics, 40(1), 21-35.

Perry, G. S., Byers, T. E., Mokdad, A. H., Serdula, M. K., \& Williamson, D. F. (1995). The Validity of Self-Reports of Past Body Weight by U.S. Adults. Epidemiology, 6(1), 61-66.

Pearlin, L. I., Schieman, S., Fazio, E. M., \& Meersman, S. C. (2005). Stress, Health, and the Life Course: Some Conceptual Perspectives. Journal of Health and Social Behavior, 
46(2), 205-219.

Rooney, B. L., \& Schauberger, C. W. (2002). Excess Pregnancy Weight Gain and Long-Term Obesity: One Decade Later. Obstetrics \&f Gynecology, 100(2), 245-252.

Rowland, M. L. (1990). Self-Reported Weight and Height. American Journal of Clinical Nutrition, 52, 1125-1133.

Saelens, B. E., \& Epstein, L. H. (1996). Reinforcing Value of Food in Obese and Non-Obese Women. Appetite, 27, 41-50.

Schanzenbach, D. W. (2009). Do School Lunches Contribute to Childhood Obesity? The Journal of Human Resources, 44(3), 684-709.

Shapiro, J. M. (2005). Is There a Daily Discount Rate? Evidence from the Food Stamp Nutrition Cycle. Journal of Public Economics, 89, 303-325.

Sherwood, L. (2007). Human Physiology: From Cells to Systems (6 ed. Vol. 6). Belmont, CA: Thomson.

Smith, P. K. (2009). Obesity Among Poor Americans: Is Public Assistance the Problem? Nashville, TN: Vanderbilt University Press.

Smith, PK, Bogin, B, \& Bishai, D. (2005). Are Time Preference and Body Mass Index Associated?: Evidence from the National Longitudinal Survey of Youth. Economics \& Human Biology, 3(2), 259-270.

Taubes, G. (2008). The Diet Delusion. London: Vermilion.

Townsend, M. S., Peerson, J., Love, B., \& Achterberg, C. (2001). Food Insecurity is Positively Related to Overweight in Women. Journal of Nutrition, 131, 1738-1745.

Troiano, R. P., Berrigan, D., Dodd, K. W., Mâsse, L. C., Tilert, T., \& McDowell, M. (2008). Physical Activity in the United States Measured by Accelerometer. Medicine $\&$ Science in Sports $\&$ Exercise, 40(1), 181-188.

Ver Ploeg, M., Mancino, L., Lin, B.-H., \& Wang, C.-Y. (2007). The Vanishing Weight Gap: Trends in Obesity Among Adult Food Stamp Participants (US) (1976-2002). Economics and Human Biology, 5, 20-36.

Ver Ploeg, M., \& Ralston, K. (2008). Food Stamps and Obesity: What Do We know? (pp. 37): Economic Research Service USDA.

Wells, J. C. K., \& Siervo, M. (2011). Obesity and Energy Balance: Is the Tail Wagging the Dog? European Journal of Clinical Nutrition, 65, 1173-1189.

Wilde, P. E., Troy, L. M., \& Rogers, B. L. (2009). Food Stamps and Food Spending: An Engel Function Approach. American Journal of Agricultural Economics, 91(2), 416-430.

Wilkinson, R. G. (1996). Unhealthy Societies: The Affictions of Inequality. New York, NY: Routledge.

Zagorsky, J. L., \& Smith, P. K. (2009). Does the U.S. Food Stamp Program Contribute to Adult Weight Gain? Economics and Human Biology, 7, 246-258. 


\section{Appendix: Dynamic Energy Balance Models}

Christiansen et al. (2005) model energy expenditure multiplicatively as $E E=P A F \times$ $R M R$, where PAF represents the physical activity factor, or the ratio of total daily energy expenditure to resting metabolic rate. For example, PAF would equal one for a person who did nothing more than lie in bed all day. Based on the amount of average daily physical activity individuals reported and the corresponding metabolic equivalents (METS) provided in NHANES we assume a PAF of 1.5, the average for women in our sample. ${ }^{32}$ Sherwood (2007) uses a functional form that is additive in RMR and energy expended in physical activity.

Combining ideas from these studies, and the daily physical activity reported in NHANES, we choose the formulation

$$
E E=1.5 R M R+A C T,
$$

where ACT denotes physical activity in excess of the normal amount of 1.5. The ACT term could be negative for a person whose activity level is less than normal. We choose this formulation because we see ACT as a choice variable that may be an unspecified function of weight. For example, an overweight woman may have below-normal activity levels because she lacks energy or she may expend more energy in physical activity than a normal-weight person because it takes more energy for her to perform a given exercise. In contrast, the term 1.5 RMR captures energy required by biophysical mechanisms to live assuming a typical

\footnotetext{
${ }^{32}$ The NHANES questionnaire asked the respondent which of the four sentences best described their usual daily activities: (i) sits most of the day and does not walk about very much, (ii) stands or walks about a lot during the day, but does not have to carry or lift things very often, (iii) lift(s) light load or has to climb stairs or hills often, or (iv) does heavy work or carries heavy loads. Each activity level had a corresponding MET score, i.e., the amount of energy relative to RMR needed to complete the reported average daily physical activity.
} 
amount of physical activity.

Chow and Hall (2008), Christiansen et al. (2005), Frankenfield, Roth-Yousy and Compher (2005), Henry (2005), and Gropper, Smith and Groff (2009) show that the relationship between RMR and body weight is approximately linear. Using this relationship and combining equations (1) and (2), we write the energy balance equation as

$$
E S=E C-A C T-1.5(\overline{R M R}-\alpha(W-\bar{W}))
$$

where $W$ denotes weight, $\bar{W}$ denotes a reference weight, $\overline{R M R}$ denotes a reference value of RMR, and $\alpha$ is a parameter that captures the energy content of the difference between weight $W$ and the reference weight $\bar{W}$. It follows that weight dynamics can be approximated well by the differential equation

$$
\frac{d W}{d t}=\rho(E C-A C T-1.5 \overline{R M R}+1.5 \alpha(W-\bar{W}))
$$

where $\rho$ is an energy conversion parameter. Chow and Hall (2008) argue that this linearized equation represents weight dynamics well, conditional on body composition and a fixed amount of physical activity. In other words, base energy expenditure $(\overline{R M R})$ varies across individuals and is driven by factors such as age, gender, physical activity, diet, existing health conditions (e.g., diabetes or asthma), and the relative amounts of fat and fat-free mass (Sherwood 2007; Gropper, Smith and Groff 2009). The solution to the differential 
equation in (A3) is

$$
\begin{aligned}
W(t) & =e^{-1.5 \rho \alpha t} W(0)+\rho \int_{0}^{t} e^{-1.5 \rho \alpha(t-s)}(E C(s)-A C T(s)+1.5(\alpha \bar{W}-\overline{R M R})) d s \\
& =e^{-1.5 \rho \alpha t} W(0)+\rho \int_{0}^{t} e^{-1.5 \rho \alpha(t-s)}(E C(s)-A C T(s)) d s+\frac{\alpha \bar{W}-\overline{R M R}}{\alpha}\left(1-e^{-\rho \alpha t}\right) .
\end{aligned}
$$

Christiansen et al. (2005) estimate that, for a typical woman, the $\alpha$ parameter in (A4), which measures the energy content of a one unit change in body mass or the energy needed to maintain the additional body weight, equals 0.048 MJ per kilogram of bodyweight per day, or $5.21 \mathrm{kcal} /$ pound/day. This estimate derives from body fat percentage and the relative energy expenditures of lean tissue and fat. When a person gains weight, the additional tissue contains a greater proportion of body fat than the existing tissue, which affects RMR because fat is less metabolically active than muscle. Based on experimental data, Christiansen et al. (2005) estimate $R M R$ in kcal per pound of body weight per day using the equation

$$
R M R=12.6 W-9.7 F M
$$

where FM represents fat-mass in pounds ${ }^{33}$ Then, based on experimental data showing that the marginal increase in fat mass per pound of body weight gain is similar for women across a wide range of body mass, they set $\partial F M / \partial W=0.76$. It follows that $\alpha=12.6-0.76 \times 9.7=5.2$. This estimate is slightly larger than the value of 4.3 that is commonly applied in clinical settings and was derived in 1919 from indirect calorimetry by Harris and Benedict.34

\footnotetext{
${ }^{33}$ The equations in Christiansen et al. (2005) are given in $\mathrm{kg} / \mathrm{MJ}$ but we convert to pound/kcal to be consistent with the rest of our analysis.

${ }^{34}$ Gropper, Smith, and Groff (2009) report the Harris-Benedict equation for women as $R M R=655.1+$
} 
Based on experimental evidence, Christiansen et al. (2005) estimate that the parameter $\rho$ equals $1 / 28.6=0.035 \mathrm{~kg} / \mathrm{MJ}$ or $0.00032 \mathrm{pound} / \mathrm{kcal}$. Substituting these parameters into (A4) implies that the change in weight over a year $(t=365)$ can be expressed as

$$
\Delta W=0.00032 \int_{0}^{365} e^{-0.0025(365-s)}(E C(s)-A C T(s)) d s-0.67 W_{0}+\mu
$$

where $\mu=0.058(\alpha \bar{W}-\overline{R M R})$ and $W_{0}$ equals weight one year prior ${ }^{35}$ This model implies that the effect on weight after one year of an increase of 10 kcal per day is

$$
10 \rho \int_{0}^{365} e^{-1.5 \rho \alpha(365-s)} d s=\frac{10}{1.5 \alpha}\left(1-e^{-1.5 \rho \alpha 365}\right)=0.77 \mathrm{lb}
$$

This number is slightly larger than the numbers implied by Hall et al. (2011), who predict a 0.5 pound $(0.23 \mathrm{~kg})$ increase in body weight after one year of consuming an additional 10 kcal per day. The steady-state weight increase in the Christansen et al. (2005) model equals $10 / 1.5 \alpha=1.28$ pounds $(0.58 \mathrm{~kg})$. Thus, the Hall et al. (2011) model has similar steady-state implications to those of Christiansen et al. (2005), but the adjustment occurs more quickly in the latter. In general, after one year we would expect

$$
\Delta W=\Delta E C\left(\rho \int_{0}^{365} e^{-1.5 \rho \alpha(365-s)} d s\right)=\frac{\Delta E C 0}{1.5 \alpha}\left(1-e^{-1.5 \rho \alpha 365}\right),
$$

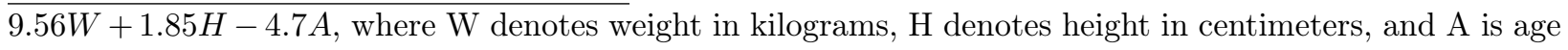
in years. We convert the coefficient on $\mathrm{W}$ to pounds by dividing by 2.2 .

${ }^{35}$ The exponent term follows from $-1.5 \rho \alpha(365-s)=-1.5(0.00032)(5.21)(365-s)=-0.0025(365-s)$ 
and a change in the steady-state weight of

$$
\Delta W=\frac{\Delta E C}{1.5 \alpha}
$$

Next, we place these models in the context of the relationship between SNAP participation and weight. Table A1 complements Table 1a by showing that, among 18-40 year-old women, SNAP participants weighed 18.4 pounds more than eligible nonparticipants during our 200106 sample period (see also Figure 1). If this difference reflects a difference in steady-state weight, then the energy balance model in (A9) implies that SNAP participants would consume about $18.4 \times 1.5 \times \alpha=144$ kcal per day more than non-participants, holding physical activity constant. If SNAP participation causes weight gain and participants had not yet reached their steady-state weight, then participants should consume an amount greater than 144 kcal more than eligible nonparticipants. For example, to gain 20 pounds in one year would require consuming an additional $261 \mathrm{kcal}$ per day.

[Table A1. Summary Statistics by Age Group]

We examined the differences in energy consumption between participants and eligible nonparticipants against this reference point, by age category. For 18-40 year olds, the average energy consumed in the food recall survey was $40 \mathrm{kcal}$ more for SNAP participants than eligible nonparticipants. This additional consumption is insignificantly different from zero and substantially smaller in magnitude than $144 \mathrm{kcal}$. However, a test of the null hypothesis that the energy consumption difference equals 144 kcal has a p-value of 0.063 , so it is not significantly different from $144 \mathrm{kcal}$. For 40-60 year olds the average weight 
difference was 14 pounds, and the average difference in calorie consumption was -44 kcal. This calorie difference implies women 40-65 years of age who participate in SNAP should have a 5.6 pound lower steady-state weight than non-participating women in this age group.

Dietary recall data are notorious for underreporting in total energy intake, and some RMR prediction equations overstate energy requirements, implying that the calculated calorie consumption could be biased down (Briefel et al. 1997; Henry 2005). For dietary recall bias to account for the observed differences in their weight and calories, the bias would need to be substantially greater for participants than nonparticipants. The probability of misreporting energy consumption increases with weight, age, gender, recent weight loss attempts, and self-perception of weight status (i.e., feeling the need to lose weight); and cultural norms may also influence the propensity for individuals to misreport their consumption habits.

We observe consumption only at the end of the year rather than as an average throughout the year. Although this quantity is a noisy estimate of average energy consumption throughout the year, it not a biased estimate of the calorie difference between participants and nonparticipants unless participants reduce their consumption at the end of the year relative to nonparticipants. Such a result could arise if participants increase their food intake while on SNAP and then reduce intake after they stop participating. To check this, we estimated the difference in calorie consumption between nonparticipants and those who participated only in the past month rather than at some point in the past year. We found that women who participated only in the previous month consumed 143 calories less per day (a statistically insignificant difference) than nonparticipants.

Apart from food intake, energy imbalance can also arise from a change in physical activity. Compared with nonparticipants, SNAP participants in our sample expended 35 
fewer kcal per day in leisure time physical activity. However, the 75 kcal net difference (i.e., 35 fewer kcal expended and 40 additional kcal consumed) accounts for about half of the 144 excess kcal needed to account for the 18 pound difference (for women aged 18-40 years) in body weight between participants and nonparticipants (we would expect a 5.7 pound weight gain after 1 year and a 9.6 pound increase in steady-state weight for an increase of $75 \mathrm{kcal}$ ).

Equations (A4) and (A6) are linearized approximations to a nonlinear dynamic energy balance function parameterized using values for a normal weight woman with normal activity level. For obese individuals, a relatively greater proportion of any gains in body weight goes to fat rather than to lean tissue (Christiansen et al. 2005). This difference has the effect of decreasing the values of $\rho$ and $\alpha$, implying a greater steady-state weight increase for a given increase in calories per day, and a slower adaptation to that steady state. Table 4 in Christiansen et al. (2005) implies that for a morbidly obese person, $\alpha=2.93 \mathrm{kcal} /$ pound/day and $\rho=0.00026$ pound $/ \mathrm{kcal}$. With these parameters, the steady state weight increase from a permanent $10 \mathrm{kcal} /$ day increase in energy consumption equals $10 / 1.5 \alpha=2.28$ pounds with an increase of 0.78 pounds after the first year. Thus, to gain 20 pounds in one year would require consuming an additional $258 \mathrm{kcal}$ per day; a 20 pound steady-state weight increase could be achieved with a permanent $87.9 \mathrm{kcal}$ per day increase in food intake. However, these parameters apply to only a few observations in our sample, so they cannot be used to explain the average differences in weight between participants and nonparticipants. 


\section{Tables and Figures}

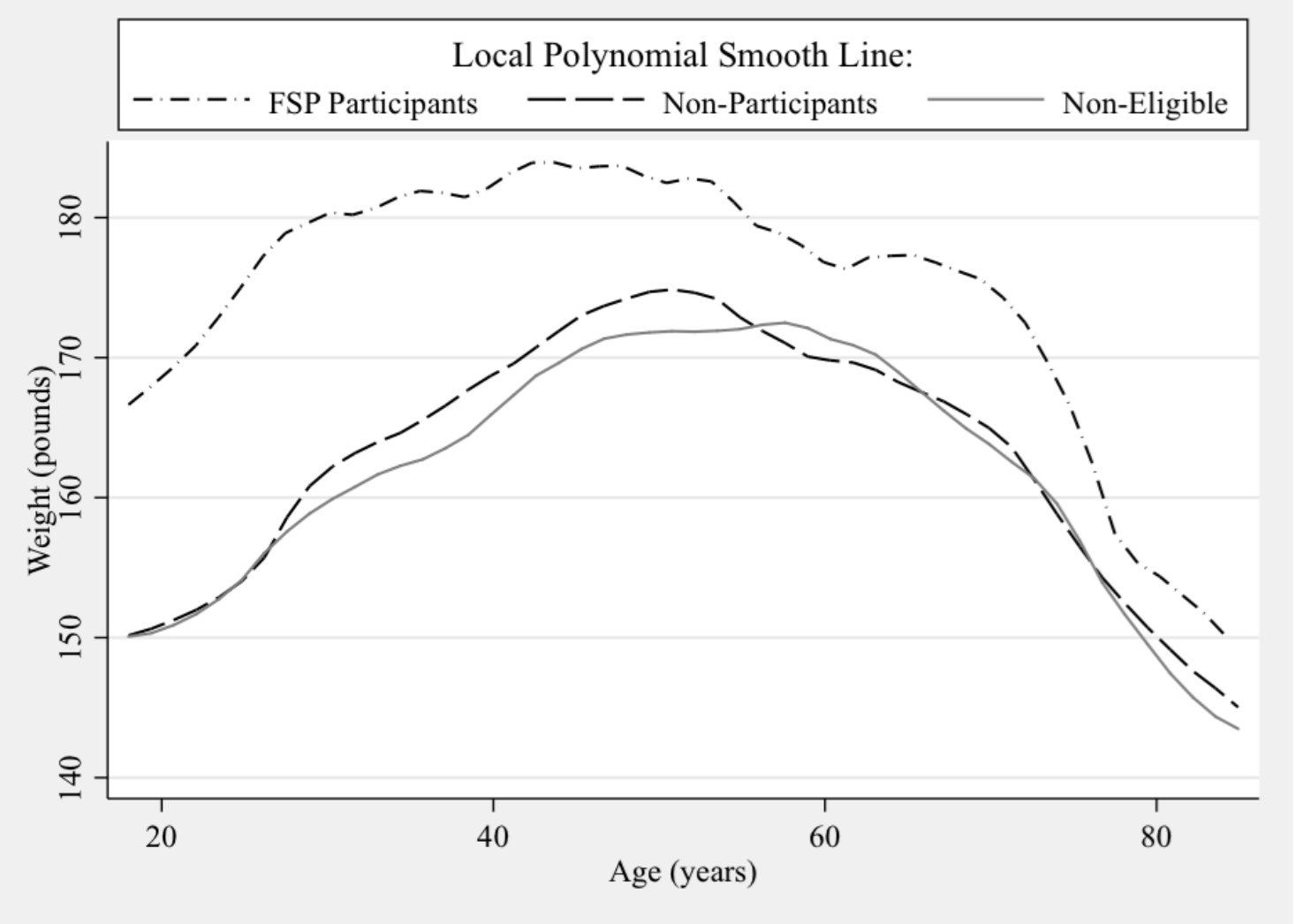

Figure 1: Weight and Age for Women by SNAP Status

Notes: Data pooled from the 2001-2002, 2003-2004, and 2005-2006 NHANESs. Women who reported having a household income at or below $185 \%$ of the federal poverty threshold were considered eligible and women above this threshold were considered ineligible. We use the "twoway lpoly" Stata command with epanechnikov kernel functions, local mean smoothing, and the rule-of-thumb bandwidth estimator (the default options). 


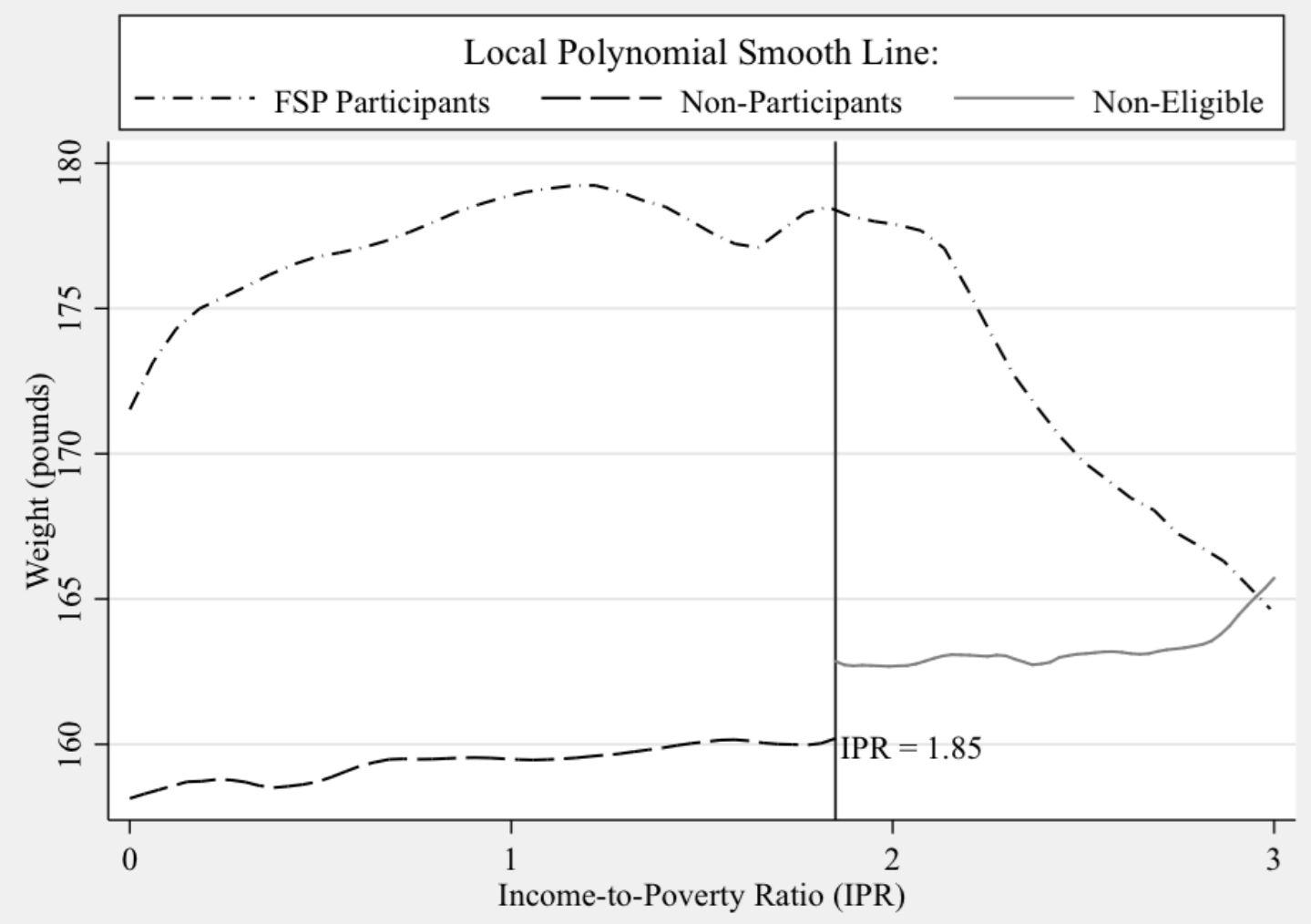

Figure 2: Weight by Income-to-Poverty Ratio for Women by SNAP Status 
Table 1a. Summary Statistics for Low-Income Women Ages 18-70

\begin{tabular}{lccc} 
& Participants & Non-participants & Difference \\
\cline { 2 - 4 } SNAP participation spell length (months) & 7.61 & & \\
Weight (pounds) & $(0.27)$ & & \\
& 179.18 & $(163.69$ & $15.49^{* *}$ \\
Age (years) & $(2.50)$ & $(1.47)$ & $(2.56)$ \\
& 37.17 & 39.33 & $-2.16^{*}$ \\
Change in weight in past year (pounds) & $(0.58)$ & $(0.72)$ & $(0.82)$ \\
& 6.73 & 4.85 & 1.88 \\
Energy expended in daily LTPA & $(1.34)$ & $(0.66)$ & $(1.43)$ \\
& 121.13 & 155.69 & -34.57 \\
Daily physical activity level (METS) & $(12.27)$ & $(19.04)$ & $(20.15)$ \\
& 1.49 & 1.51 & $0.02^{* *}$ \\
Sits most of the day & $(0.004)$ & $(0.003)$ & $(0.005)$ \\
& 0.32 & 0.22 & $0.10^{* *}$ \\
Lifts light loads/climbs stairs daily & $(0.02)$ & $(0.02)$ & $(0.03)$ \\
& 0.13 & 0.18 & $-0.05^{*}$ \\
Total daily energy (kcals) & $(0.02)$ & $(0.01)$ & $(0.02)$ \\
& $1,849.55$ & $1,809.39$ & 40.16 \\
Daily intake of sugar (grams) & $(36.42)$ & $(29.83)$ & $(54.38)$ \\
T2D & 123.02 & 113.28 & $9.74^{*}$ \\
& $(3.95)$ & $(1.97)$ & $(4.73)$ \\
Metabolic Syndrome ${ }^{a}$ & 0.09 & 0.08 & 0.01 \\
& $(0.01)$ & $(0.01)$ & $(0.01)$ \\
Elevated WC (WC $>$ 88cm) & 0.59 & 0.49 & $0.10^{* *}$ \\
Family history of T2D & $(0.03)$ & $(0.02)$ & $(0.03)$ \\
& 0.70 & 0.59 & $0.11^{* *}$ \\
Non-Hispanic black & $(0.02)$ & $(0.02)$ & $(0.03)$ \\
Mexican American & 0.41 & 0.38 & 0.03 \\
Other race & $(0.02)$ & $(0.02)$ & $(0.03)$ \\
& 0.35 & 0.14 & $0.20^{* *}$ \\
& $(0.04)$ & $(0.02)$ & $(0.03)$ \\
& 0.09 & 0.15 & $-0.06^{* *}$ \\
& $(0.02)$ & $(0.02)$ & $(0.01)$ \\
& 0.12 & 0.14 & -0.01 \\
& $(0.03)$ & $(0.2)$ & $(0.02)$ \\
\hline
\end{tabular}




\begin{tabular}{|c|c|c|c|}
\hline \multirow{3}{*}{ Income to Poverty Ratio } & Participants & Non-participants & Difference \\
\hline & 0.80 & 1.09 & $-0.29^{* *}$ \\
\hline & $(0.03)$ & $(0.02)$ & $(0.03)$ \\
\hline \multirow[t]{2}{*}{ High school graduate } & 0.29 & 0.28 & 0.01 \\
\hline & $(0.03)$ & $(0.02)$ & $(0.03)$ \\
\hline \multirow[t]{2}{*}{ College Graduate } & 0.04 & 0.11 & $-0.07^{* *}$ \\
\hline & $(0.01)$ & $(0.01)$ & $(0.02)$ \\
\hline \multirow[t]{2}{*}{ Married } & 0.35 & 0.48 & $-0.14^{* *}$ \\
\hline & $(0.03)$ & $(0.02)$ & $(0.04)$ \\
\hline \multirow[t]{2}{*}{ US Citizen } & 0.92 & 0.84 & 0.08 \\
\hline & $(0.01)$ & $(0.02)$ & $(0.02)$ \\
\hline \multirow[t]{2}{*}{ Renter } & 0.71 & 0.47 & $0.24^{* *}$ \\
\hline & $(0.03)$ & $(0.02)$ & $(0.03)$ \\
\hline \multirow[t]{2}{*}{ Doesn't rent or own home } & 0.02 & 0.05 & $-0.03^{*}$ \\
\hline & $(0.01)$ & $(0.01)$ & $(0.01)$ \\
\hline \multirow[t]{2}{*}{ Current smoker } & 0.47 & 0.27 & $0.20^{* *}$ \\
\hline & $(0.03)$ & $(0.02)$ & $(0.03)$ \\
\hline \multirow[t]{2}{*}{ Alcoholic drinks per day } & 1.70 & 1.37 & $0.33^{* *}$ \\
\hline & $(0.10)$ & $(0.08)$ & $(0.10)$ \\
\hline \multirow[t]{2}{*}{ \# meals per week away-from-home } & 1.55 & 2.34 & $-0.80^{* *}$ \\
\hline & $(0.09)$ & $(0.19)$ & $(0.24)$ \\
\hline \multirow[t]{2}{*}{$>3$ hours $\mathrm{TV} /$ day } & 0.67 & 0.62 & 0.04 \\
\hline & $(0.02)$ & $(0.02)$ & $(0.03)$ \\
\hline \multirow[t]{2}{*}{$>3$ hours computer/day } & 0.72 & 0.70 & 0.02 \\
\hline & $(0.03)$ & $(0.03)$ & $(0.04)$ \\
\hline \multirow[t]{2}{*}{ Youngest child $\leq 1$ year old } & 0.12 & 0.07 & 0.04 \\
\hline & $(0.02)$ & $(0.01)$ & $(0.02)$ \\
\hline \multirow[t]{2}{*}{ Youngest child $1-5$ years old } & 0.24 & 0.12 & $0.13^{* *}$ \\
\hline & $(0.02)$ & $(0.01)$ & $(0.03)$ \\
\hline \multirow[t]{2}{*}{ Currently breastfeeding } & 0.03 & 0.03 & 0.01 \\
\hline & $(0.01)$ & $(0.01)$ & $(0.01)$ \\
\hline \multirow[t]{2}{*}{ Days in the last month felt depressed } & 9.34 & 5.44 & $3.90^{* *}$ \\
\hline & $(0.60)$ & $(0.24)$ & $(0.61)$ \\
\hline \multirow[t]{2}{*}{ Thyroid condition } & 0.09 & 0.07 & 0.01 \\
\hline & $(0.02)$ & $(0.01)$ & $(0.02)$ \\
\hline Observations & 514 & 1,504 & \\
\hline
\end{tabular}

Notes: All means estimated using the survey settings in Stata 12.0. Standard errors in parentheses, ** indicates $\mathrm{p}<0.01, *$ indicates $\mathrm{p}<0.05$. (a) We were only able to identify individuals from the 2003-2004 and 2005-2006 NHANES (1,368 observations) who met the National Cholesterol Education Program ATP III guidelines criteria for metabolic syndrome. T2D = type 2 diabetes, LTPA = leisure time physical activity, and $\mathrm{WC}=$ waist circumference. 
Table 1b. Excess kcal per day required for difference in body weight Christiansen et al. (2005) kcal/day

Gain 15.5 pounds over one year 202

Gain 15.5 in pound steady-state weight $\quad 121$

Hall et al (2011)

Gain 15.5 pounds over one year $\quad 330$

Gain 15.5 pounds in steady-state weight $\quad 155$ 


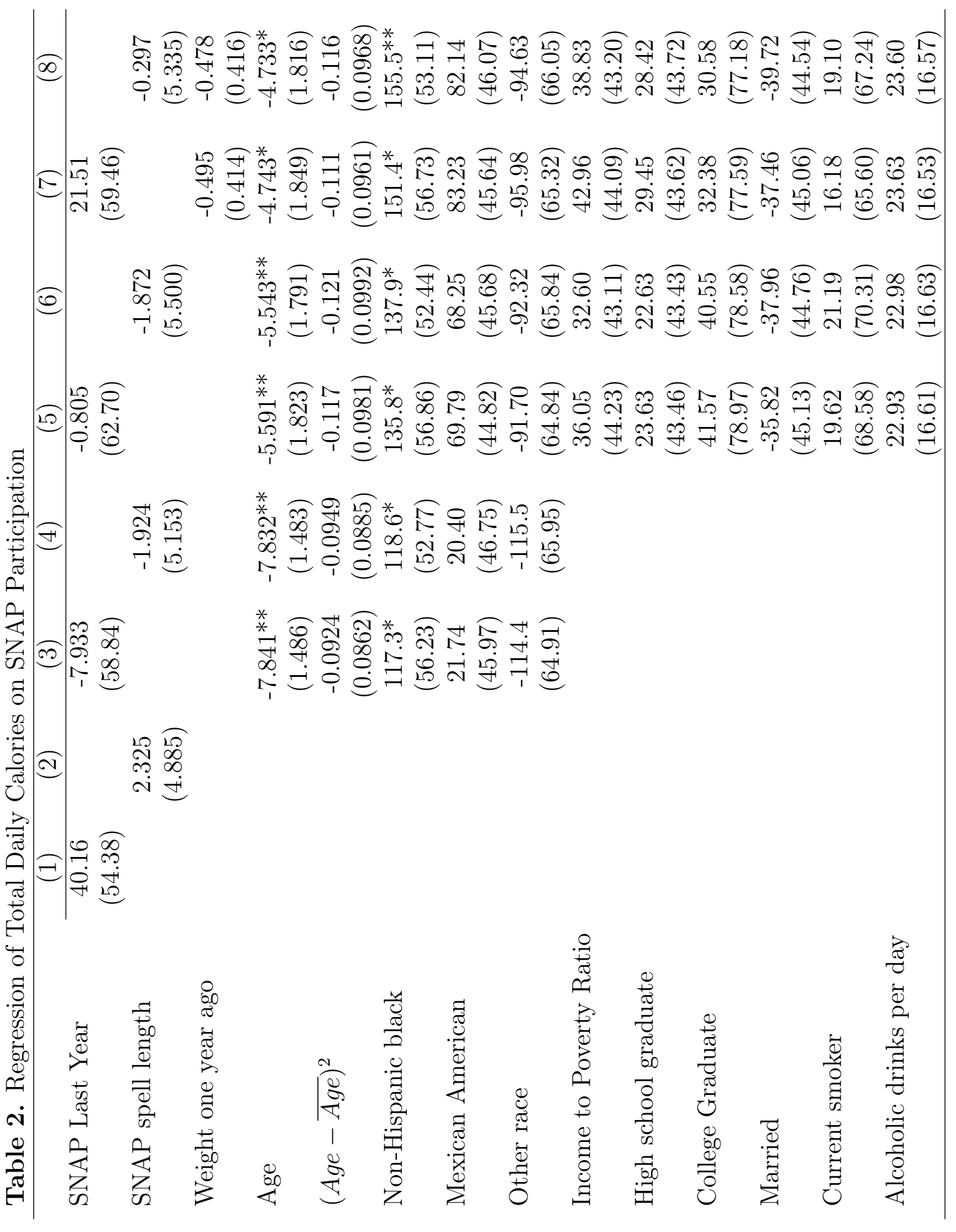




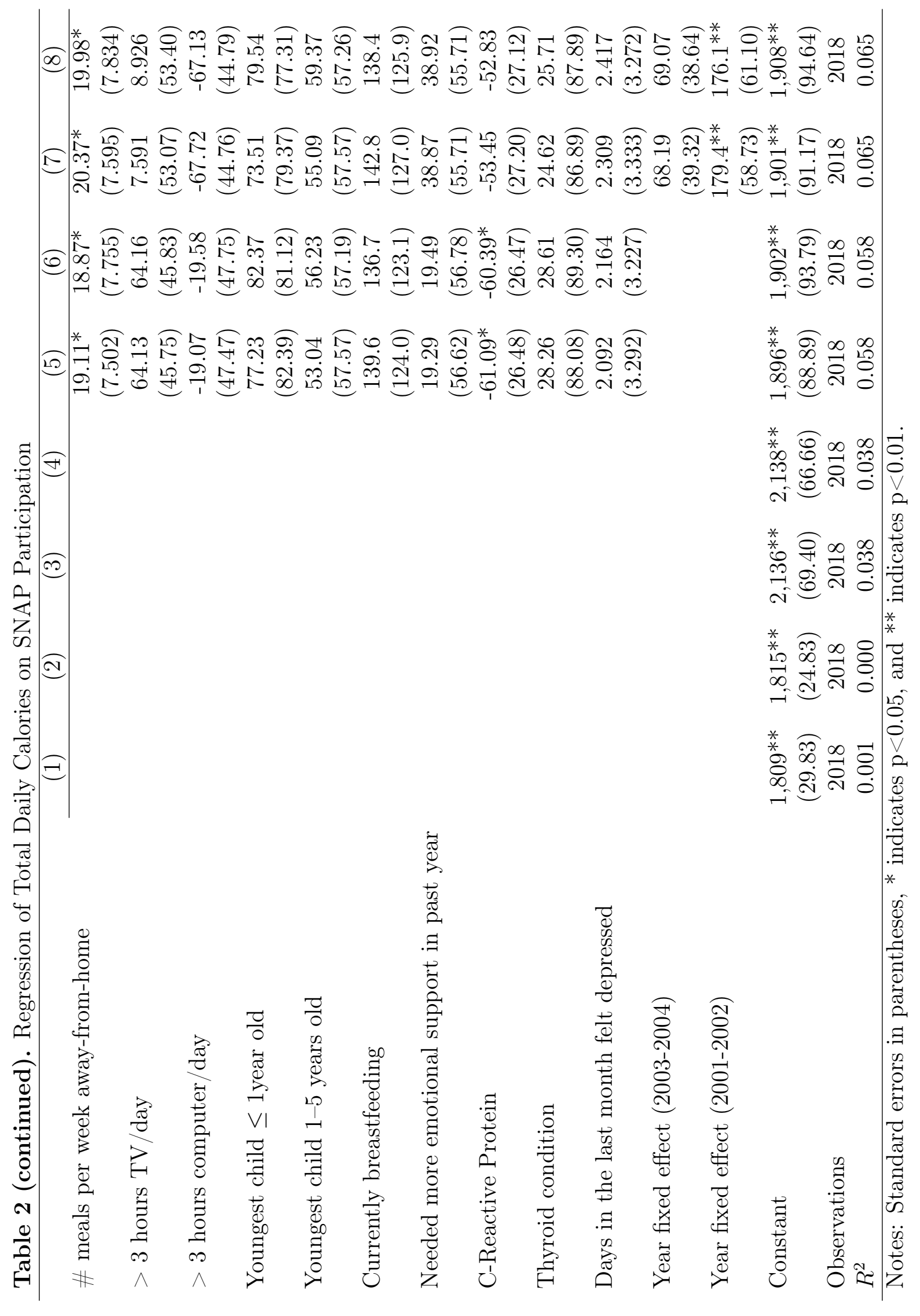




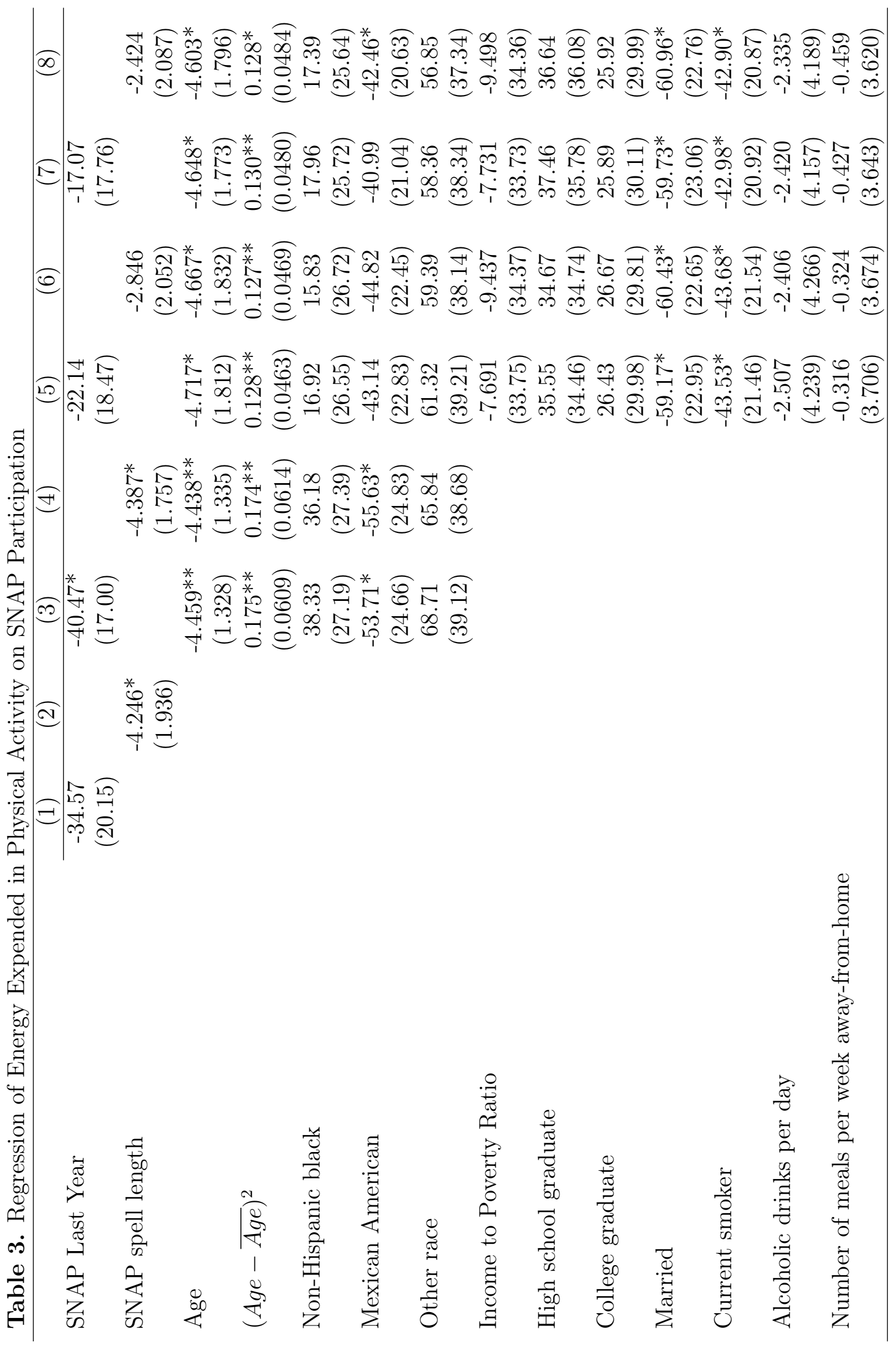




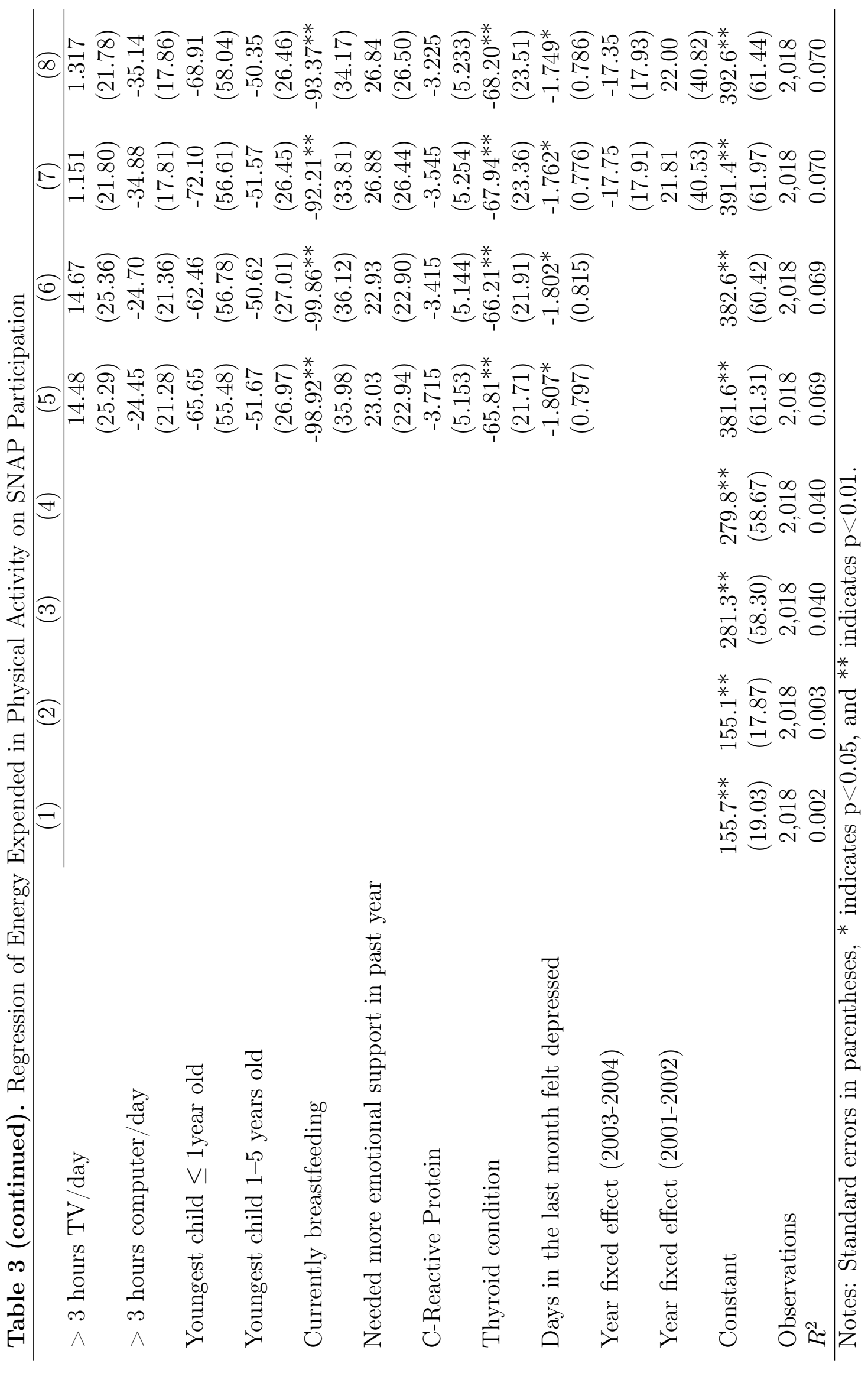




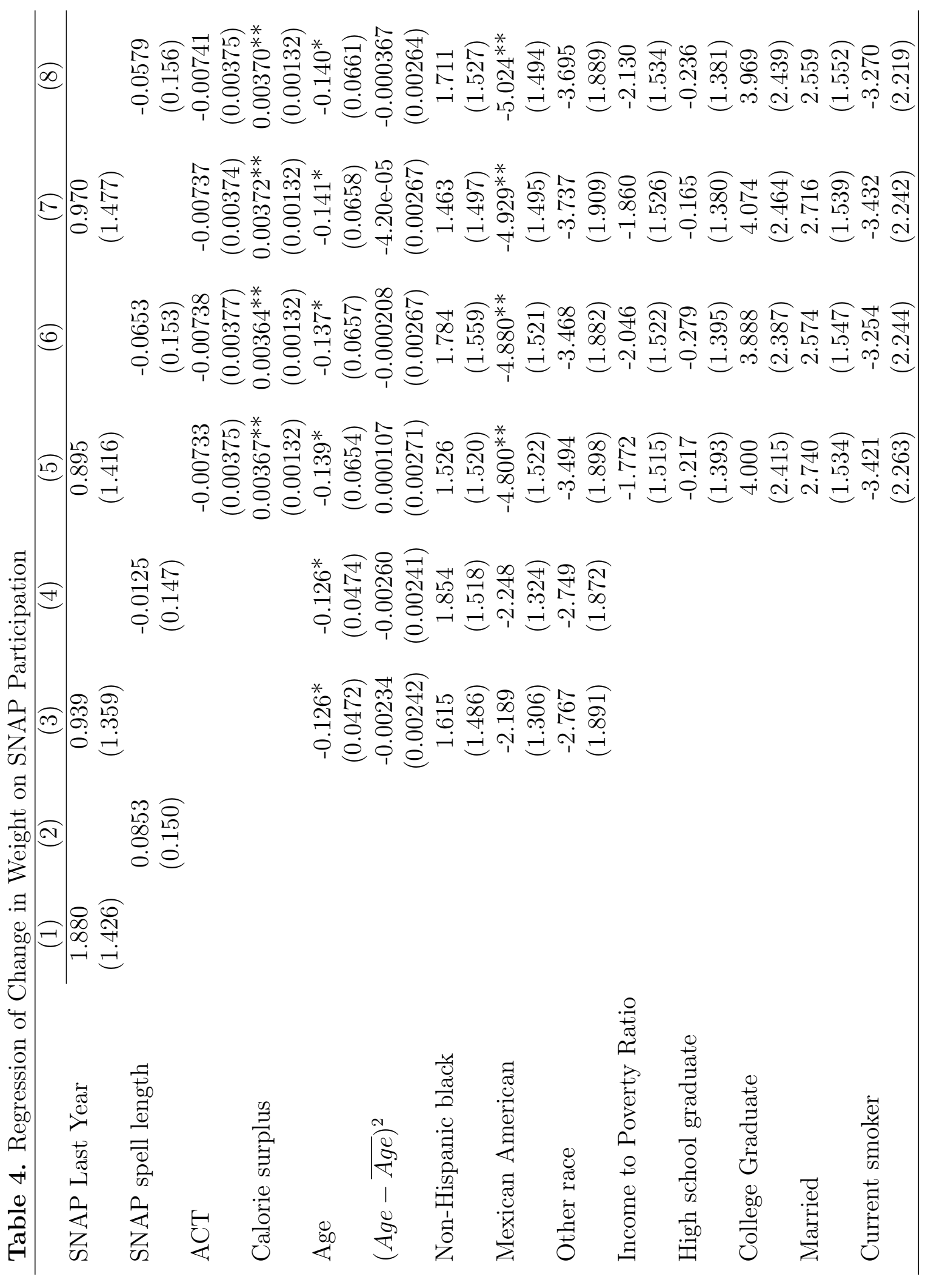




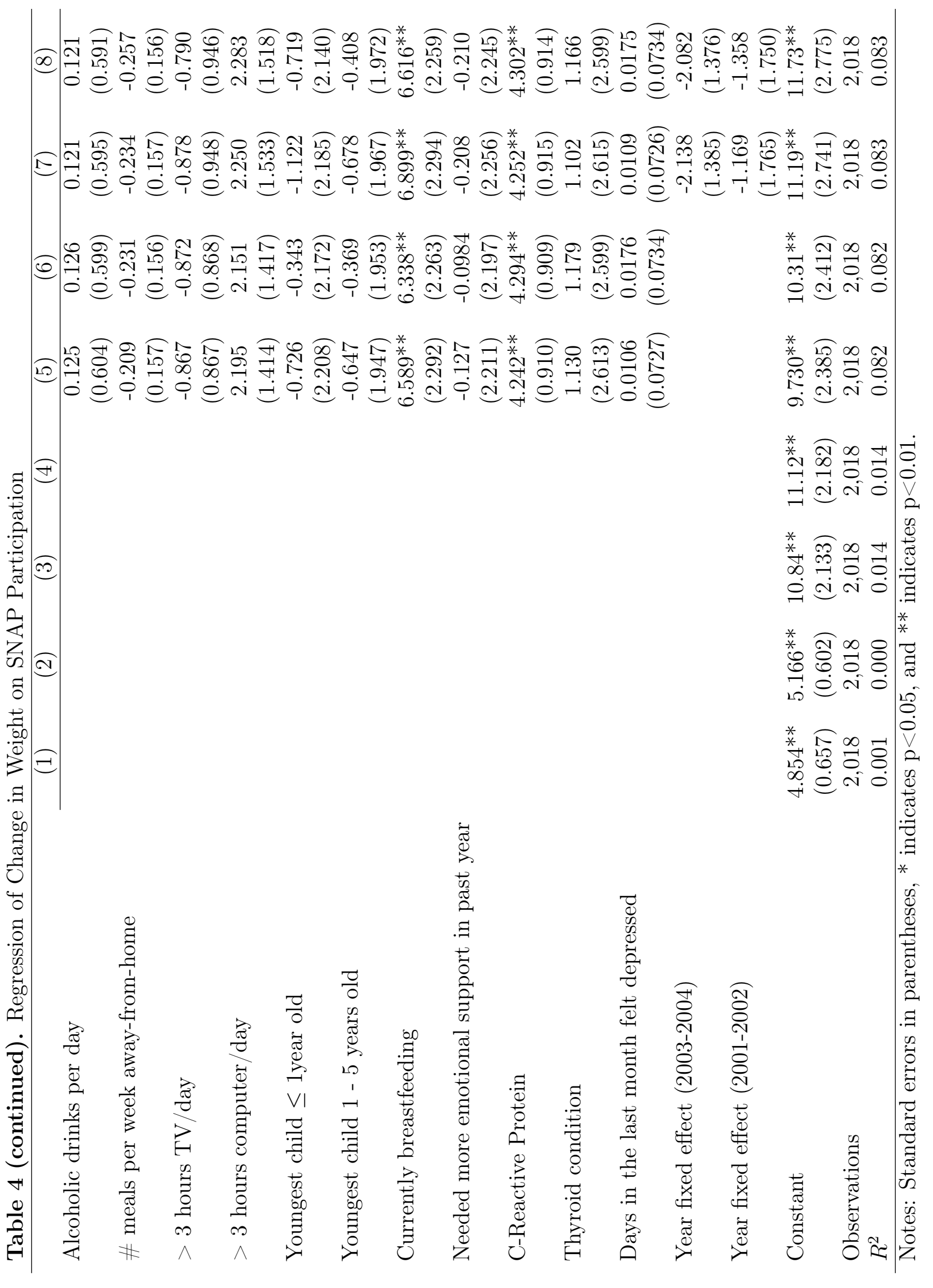


Table 5. OLS Model of SNAP Participation

\begin{tabular}{lcccc}
\hline \multirow{3}{*}{ Weight (pounds) } & $(1)$ & $(2)$ & $(3)$ & $(4)$ \\
\cline { 2 - 4 } Age & $0.001^{* *}$ & $0.0009^{* *}$ & $0.0008^{* *}$ & $0.0008^{* *}$ \\
& $(0.0002)$ & $(0.0002)$ & $(0.0002)$ & $(0.0002)$ \\
$(\text { Age }-\overline{A g e})^{2}$ & & -0.00002 & -0.0001 & -0.0003 \\
& $(0.0008)$ & $(0.0008)$ & $(0.0008)$ \\
Non-Hispanic black & $-0.0002^{* *}$ & $-0.0002^{* *}$ & $-0.0002^{* *}$ \\
& & $(0.00004)$ & $(0.00004)$ & $(0.00004)$ \\
Mexican American & $0.104^{* *}$ & $0.111^{* *}$ & $0.119^{* *}$ \\
& $(0.032)$ & $(0.032)$ & $(0.04)$ \\
Other race & 0.007 & 0.020 & 0.04 \\
& $(0.026)$ & $(0.024)$ & $(0.03)$ \\
Income-to-poverty Ratio & $0.058^{*}$ & $0.064^{*}$ & $0.07^{*}$ \\
& $(0.027)$ & $(0.03)$ & $(0.03)$ \\
High school graduate & $-0.166^{* *}$ & $-0.161^{* *}$ & -0.17 \\
& & $(0.022)$ & $(0.021)$ & $(0.02)$ \\
College graduate & -0.028 & -0.029 & -0.03 \\
& $(0.019)$ & $(0.018)$ & $(0.02)$ \\
Married & $-0.081^{*}$ & -0.068 & -0.06 \\
& $(0.037)$ & $(0.035)$ & $(0.04)$ \\
US Citizen & $-0.072^{* *}$ & $-0.078^{* *}$ & $-0.078^{* *}$ \\
Renter & $(0.025)$ & $(0.026)$ & $(0.03)$ \\
& $0.162^{* *}$ & $0.142^{* *}$ & $0.139^{* *}$ \\
Don't rent or own home & $(0.029)$ & $(0.03)$ & $(0.03)$ \\
& $0.131^{* *}$ & $0.140^{* *}$ & $0.139^{* *}$ \\
& $(0.021)$ & $(0.021)$ & $(0.02)$ \\
& -0.029 & -0.017 & -0.04 \\
& $(0.034)$ & $(0.034)$ & $(0.04)$ \\
\hline
\end{tabular}


Table 5 (continued). OLS Model of SNAP Participation

\begin{tabular}{|c|c|c|c|c|}
\hline \multirow{3}{*}{ Current smoker } & $(1)$ & $(2)$ & $(3)$ & $(4)$ \\
\hline & & $0.112^{* *}$ & $0.110^{* *}$ & $0.106^{* *}$ \\
\hline & & $(0.025)$ & $(0.024)$ & $(0.02)$ \\
\hline \multirow{2}{*}{ Alcoholic drinks per day } & & -0.006 & -0.006 & -0.01 \\
\hline & & $(0.006)$ & $(0.006)$ & $(0.01)$ \\
\hline \multirow[t]{2}{*}{ \# meals per week away-from-home } & & $-0.014^{* *}$ & $-0.015^{* *}$ & $-0.014^{* *}$ \\
\hline & & $(0.004)$ & $(0.004)$ & $(0.003)$ \\
\hline \multirow[t]{2}{*}{$>3$ hours $\mathrm{TV} /$ day } & & 0.000 & -0.001 & 0.01 \\
\hline & & $(0.02)$ & $(0.02)$ & $(0.02)$ \\
\hline \multirow[t]{2}{*}{$>3$ hours computer/day } & & -0.015 & -0.020 & -0.01 \\
\hline & & $(0.02)$ & $(0.02)$ & $(0.02)$ \\
\hline \multirow[t]{2}{*}{ Youngest child $\leq 1$ year old } & & $0.268^{* *}$ & $0.262^{* *}$ & $0.262^{* *}$ \\
\hline & & $(0.041)$ & $(0.042)$ & $(0.04)$ \\
\hline \multirow[t]{2}{*}{ Youngest child $1-5$ years old } & & $0.177^{* *}$ & $0.177^{* *}$ & $0.170 * *$ \\
\hline & & $(0.039)$ & $(0.038)$ & $(0.04)$ \\
\hline \multirow[t]{2}{*}{ Currently breastfeeding } & & $-0.192^{* *}$ & $-0.187^{* *}$ & $-0.171^{* *}$ \\
\hline & & $(0.058)$ & $(0.058)$ & $(0.06)$ \\
\hline \multirow[t]{2}{*}{ Metropolitan area indicator } & & & -0.034 & -0.01 \\
\hline & & & $(0.028)$ & $(0.03)$ \\
\hline \multirow[t]{2}{*}{ County child poverty rate } & & & 0.00009 & 0.005 \\
\hline & & & $(0.003)$ & $(0.003)$ \\
\hline \multirow[t]{2}{*}{ County median household income } & & & -0.000002 & -0.000001 \\
\hline & & & $(0.000001)$ & $(0.000002)$ \\
\hline \multirow[t]{2}{*}{ County unemployment rate } & & & 0.006 & -0.01 \\
\hline & & & $(0.008)$ & $(0.01)$ \\
\hline \multirow[t]{2}{*}{ \# SNAP authorized stores in county } & & & $-0.00002^{* *}$ & $-0.00002^{* *}$ \\
\hline & & & $(0.00001)$ & $(0.00001)$ \\
\hline \multirow[t]{2}{*}{ State food sales tax indicator } & & & -0.002 & 0.09 \\
\hline & & & $(0.025)$ & $(0.05)$ \\
\hline State fixed effects? & No & No & No & Yes \\
\hline \multirow[t]{2}{*}{ Constant } & 0.020 & 0.09 & 0.185 & 0.06 \\
\hline & $(0.0392)$ & $(0.054)$ & $(0.125)$ & $(0.12)$ \\
\hline Observations & 2,375 & 2,375 & 2,375 & 2,375 \\
\hline$R^{2}$ & 0.02 & 0.23 & 0.24 & 0.26 \\
\hline
\end{tabular}


Table A1.Summary Statistics by Age Group

\begin{tabular}{|c|c|c|c|}
\hline & \multicolumn{3}{|c|}{ Panel $A: 18-40$ years of age } \\
\hline & Participants & Non-participants & Difference in Means \\
\hline \multirow{2}{*}{ SNAP participation spell length (months) } & 7.57 & - & - \\
\hline & $(0.38)$ & - & - \\
\hline \multirow[t]{2}{*}{ Weight (pounds) } & 175.77 & 157.4 & $18.37^{* *}$ \\
\hline & $(3.13)$ & $(1.95)$ & $(3.37)$ \\
\hline \multirow[t]{2}{*}{ Change in weight in past year (pounds) } & 8.83 & 5.82 & 3.01 \\
\hline & $(1.49)$ & $(0.91)$ & $(1.65)$ \\
\hline \multirow[t]{2}{*}{ Vigorous physical activity } & 0.24 & 0.39 & $-0.15^{* *}$ \\
\hline & $(0.03)$ & $(0.03)$ & $(0.04)$ \\
\hline \multirow[t]{2}{*}{ Moderate physical activity } & 0.47 & 0.56 & -0.1 \\
\hline & $(0.05)$ & $(0.03)$ & $(0.05)$ \\
\hline \multirow[t]{2}{*}{ Total daily calories (kcals) } & $1,956.44$ & $1,916.71$ & 39.73 \\
\hline & $(39.64)$ & $(46.23)$ & (72.78) \\
\hline \multirow[t]{2}{*}{ Observations } & 318 & 839 & \\
\hline & \multicolumn{3}{|c|}{ Panel B: $41-60$ years of age } \\
\hline \multirow[t]{2}{*}{ SNAP participation spell length (months) } & 7.66 & - & - \\
\hline & -0.55 & - & - \\
\hline \multirow[t]{2}{*}{ Weight (pounds) } & 186.71 & 172.72 & $13.99^{* *}$ \\
\hline & $(3.92)$ & $(3.28)$ & $(4.87)$ \\
\hline \multirow[t]{2}{*}{ Change in weight in past year (pounds) } & 3.12 & 4.79 & -1.67 \\
\hline & $(2.54)$ & $(1.67)$ & $(3.21)$ \\
\hline \multirow[t]{2}{*}{ Vigorous physical activity } & 0.19 & 0.21 & -0.03 \\
\hline & $(0.04)$ & $(0.03)$ & $(0.04)$ \\
\hline \multirow[t]{2}{*}{ Moderate physical activity } & 0.45 & 0.49 & -0.04 \\
\hline & $(0.05)$ & $(0.04)$ & $(0.07)$ \\
\hline \multirow[t]{2}{*}{ Total daily calories (kcals) } & $1,681.16$ & $1,725.18$ & -44.02 \\
\hline & $(66.35)$ & (26.36) & $(77.25)$ \\
\hline Observations & 142 & 391 & \\
\hline
\end{tabular}



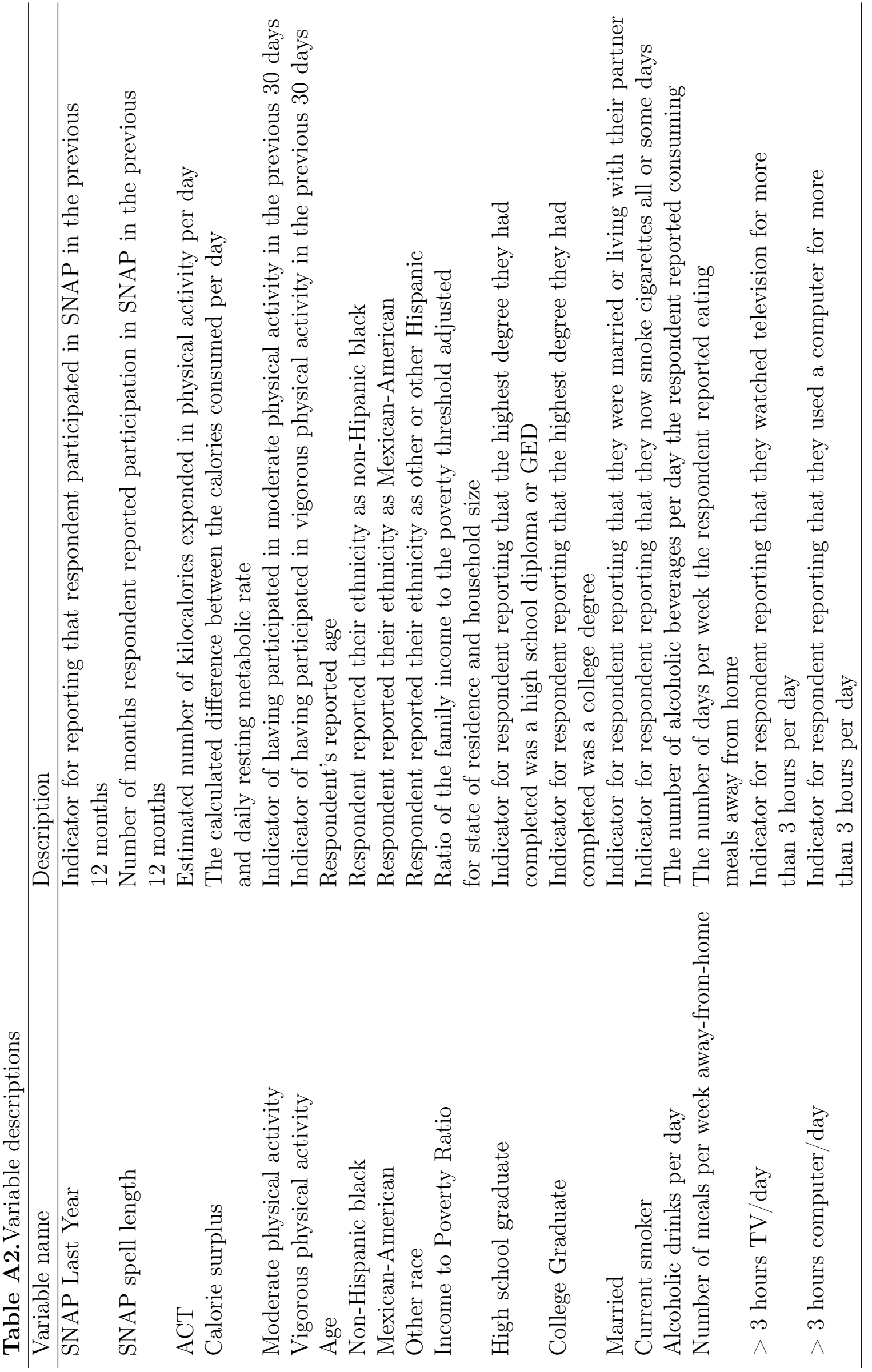


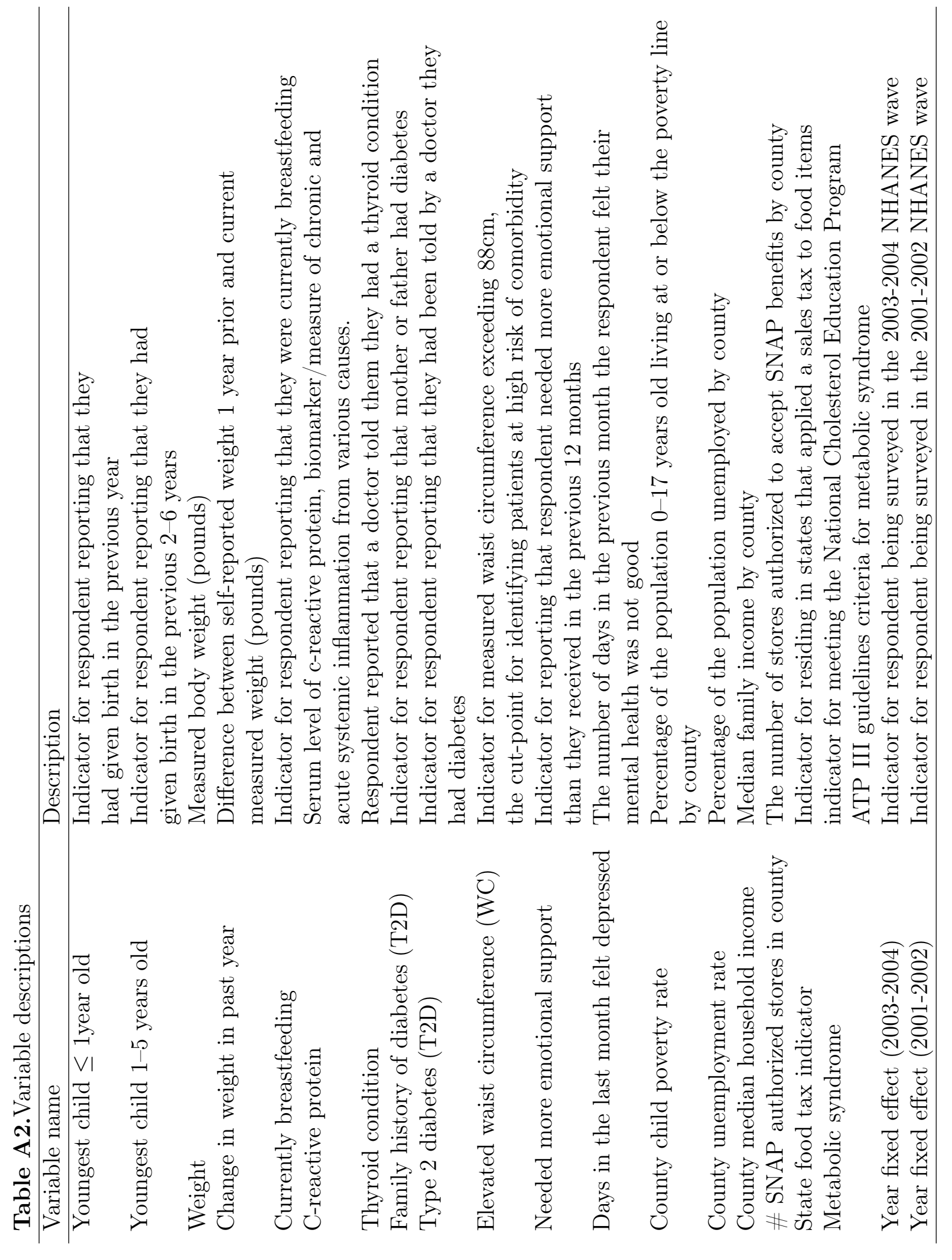

